

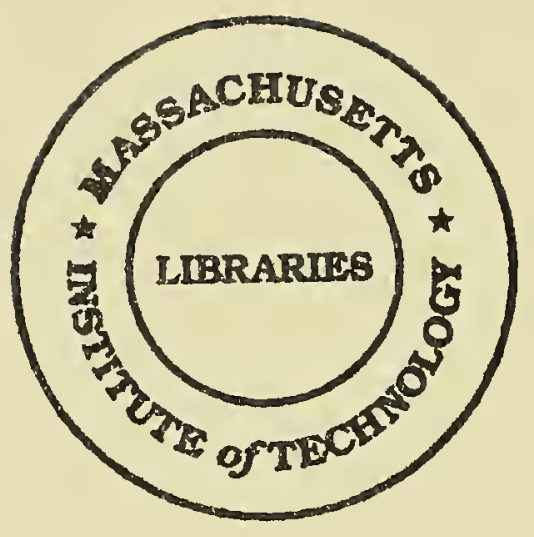




Massachusetts Institute of Technology

Department of Economics Working Paper Series

\title{
The Interest Rate, Learning, and Inventory Investment
}

\author{
Louis J. Maccini \\ Bartholomew Moore \\ Huntley Schaller
}

Working Paper 03-04

January 2003

\author{
Room E52-251 \\ 50 Memorial Drive \\ Cambridge, MA 02142
}

This paper can be downloaded without charge from the Social Science Research Network Paper Collection at http://ssrn.com/abstract_id $=372844$ 
Digitized by the Internet Archive in 2011 with funding from

Boston Library Consortium Member Libraries

http://www.archive.org/details/interestratelear00macc 
January 2003.

\title{
The Interest Rate, Learning, and Inventory Investment
}

\author{
Louis J. Maccini \\ (Corresponding author) \\ Department of Economics \\ Johns Hopkins University \\ 3400 N. Charles Street \\ Baltimore, MD 21218 \\ (410) 516-7607 \\ maccini@jhu.edu
}

\author{
Bartholomew Moore \\ Department of Economics \\ Fordham University \\ 441 East Fordham Road \\ The Bronx, NY 10458 \\ (718) 817-3564 \\ bmoore@fordham.edu
}

\author{
Huntley Schaller \\ Department of Economics \\ Massachusetts Institute of Technology \\ 50 Memorial Drive \\ Cambridge, MA 02142-1347 \\ (617) 452-4368 \\ schaller@mit.edu
}

[JEL Classification: E22. Keywords: Inventories, Interest Rates, Learning]

We thank Heidi Portuondo for research assistance. For helpful comments we thank Ken West, our discussant at the 2002 AEA meetings, Serena Ng, and seminar participants at Brandeis University and the XII symposium of the International Society for Inventory Research. Schaller acknowledges the financial support of the SSHRC for his research program. 



\begin{abstract}
We derive parametric tests for the role of the interest rate in specifications based on the firm's optimization problem. These Euler equation and decision rule tests mirror earlier evidence, finding little role for the interest rate. We present a simple and intuitively appealing explanation, based on regime switching in the real interest rate and learning, of why tests based on the stock adjustment model, the Euler equation, and decision rule - all of which emphasize short-run fluctuations in inventories and the interest rate - are unlikely to uncover a relationship. Our analysis suggests that inventories will not respond much to short-run fluctuations in the interest rate, but they should respond to long-run movements. Both simple and sophisticated tests confirm our predictions and show a highly significant long-run relationship between inventories and the interest rate. A formal model of our explanation yields a previously untested implication that is supported by the data.
\end{abstract}





\section{Introduction}

In their survey of inventory research, Blinder and Maccini (1991) observe that an important puzzle with empirical research on inventories is that the real interest rate seems to have little impact on inventory investment. But, very little research on this issue has been conducted over the last decade. As an indicator of the lack of work, the recent survey by Ramey and West (1999) barely mentions the effect of interest rates on inventories.

The issue is a puzzle for two reasons. First, the lack of an effect of the real interest rate on inventory investment severs one of the conventional channels through which monetary policy influences spending. Monetary policy is implemented by changing short-term interest rates, which standard theory predicts should influence inventory investment spending. Second, the financial press is replete with statements by business people asserting that higher interest rates induce firms to cut inventory holdings. Although it is sometimes not clear whether the interest rate under discussion is real or nominal, there is nonetheless the perception of an inverse relationship between inventory investment and interest rates. Yet, almost no evidence exists for such an effect.

Earlier empirical work with inventories utilized flexible accelerator or stock adjustment models. Among the key issues investigated in this literature was the relationship between inventory investment and interest rates. See Akhtar (1983), Blinder (1986a), Irvine (1981), Maccini and Rossana (1984), and Rossana (1990) for relatively recent studies using this approach. ${ }^{1}$ These studies typically assumed that "desired stocks" depend on the current expected real interest rate as well as current expected sales and

\footnotetext{
' Stock adjustment models were first used in empirical work with inventories by Lovell (1961). See Akhtar (1983) for a survey of the relevant literature prior to the eighties.
} 
expected input prices. Current expected real rates were related to actual rates through distributed lag relationships and empirical work proceeded. These studies, however, generally failed to establish substantial and systematic evidence of a relationship between the real interest rate and inventory investment, especially with finished goods inventories in manufacturing. Furthermore, the literature was subject to the criticism that it lacked a basis in explicit optimization.

In the eighties, the linear-quadratic model of inventory behavior combined with rational expectations began to be applied to empirical work on inventories. The linearquadratic model of inventory behavior was developed by Holt, Modigliani, Muth and Simon (1960), and was revived in the economics literature in the eighties by Blinder $(1982,1986 b)$ who used the model in analytical work. When combined with rational expectations, the model is a very fruitful framework for empirical work. However, the relationship between the real interest rate and inventory movements was not a key issue under investigation in empirical research with the linear-quadratic model. Rather, research focused on attempts to explain why production seemed to fluctuate more than sales, which contradicts the production-smoothing motive for holding inventories, and why inventory stocks seemed to exhibit such persistence.

Two approaches were employed in empirical research. One approach estimated Euler equations using generalized methods of moments techniques. Contributions using this approach include Durlauf and Maccini (1995), Eichenbaum (1989), Kashyap and Wilcox (1993), Kollintzas (1995), Krane and Braun (1991), Ramey (1991), and West (1986). In this work, it proved difficult to estimate the structural parameters of interest when the discount factor, which is defined by the real interest rate, is allowed to vary. 
Hence, researchers invariably assumed that the discount factor is a given, known value, which of course eliminates by assumption any effect of the real interest rate on inventory investment.

Given the finite sample problems with generalized methods of moments applied to Euler equations, another approach used in empirical work with the linear-quadratic model was to solve for the optimal choice of inventories, that is, for the decision rule, and to estimate it using maximum likelihood techniques ${ }^{2}$. See Blanchard (1983), Fuhrer, Moore and Schuh (1995), and Humphreys, Maccini and Schuh (2001). However, solving for the decision rule requires an Euler equation that is linear in its variables. Since Euler equations are nonlinear in the discount rate, and therefore in the real interest rate, researchers again resorted to a constant and known discount rate for reasons of tractability.

A few studies departed from the linear-quadratic framework and allowed real interest rates to vary. Miron and Zeldes (1988) utilize an approach with a Cobb-Douglas production function that emphasizes cost shocks and seasonal fluctuations. Kahn (1992) and Bils and Kahn (2000) focus on a more rigorous treatment of the stockout avoidance motive. In these studies, when a check was made, no effect on the empirical implications of the model was found when the real interest rate was allowed to vary or was held constant. $^{3}$ An exception is Ramey (1989) who developed a model that treats inventory stocks as factors of production, and found evidence of interest rate effects through relevant imputed rental rates.

\footnotetext{
${ }^{2}$ As is well known, the decision rule for optimal inventories can be converted into a stock adjustment model. A key difference between this approach and the earlier stock adjustment principles is that the desired stock now depends on expected future sales, input prices, and real interest rates as well as current expected values.

${ }^{3}$ See Miron and Zeldes (1988) and Kahn (1992).
} 
Given the lack of strong evidence of a relationship between the real interest rate and inventory movements, a number of authors conjectured that the problem with the standard model is that it assumes perfect capital markets, so that firms may borrow or lend as much as they want at given interest rates. Rather, they argued that capital market imperfections arising from asymmetric information will impose finance constraints on the firm's inventory decision. These constraints suggest that the cost of external finance to the firm is inversely related to the firm's internal financial position, as measured by liquid assets or cash flow. See Kashyap, Lamont and Stein (1994), Gertler and Gilchrist (1994), and Carpenter, Fazzari and Petersen (1994) for contributions to this approach. They find that such financial variables do have an influence on inventory movements of small firms but not of large firms. This leaves open the relationship between the real interest rate and inventory movements for large firms and in the aggregate.

The purpose of this paper is to take a fresh look at the relationship between the real interest rate and inventory investment. This is obviously an important issue for empirical work on the transmission and effectiveness of monetary policy, and complements the empirical work underway with interest rate rules as descriptions of monetary policy. We begin by extending the typical approach taken with the linearquadratic model, specifically to obtain a specification in which the interest rate appears in a separate term with its own coefficient. Essentially, this involves an appropriate linear approximation of the Euler equation in the real interest rate. This enables us to solve for the optimal level of inventories as a linear function of the real interest rate and other variables. 
Using the linearized Euler equation as a starting point, we are able to derive specifications that allow us to parametrically estimate the effect of the interest rate on inventories. We use two approaches - the linearized Euler equation and the firm's decision rule for inventories (which can be derived from the linearized Euler equation). We undertake empirical work with monthly data on inventories for the nondurable aggregate of U.S. manufacturing for the period 1959-1999. The results reinforce the existing puzzle: these specifications reveal no significant effect of the interest rate.

Why don't the Euler equation and decision rule show an effect of the real interest rate on inventories? We suggest that the answer lies in the behavior of the interest rate, which displays transitory variation around highly persistent mean values (e.g., persistently negative real interest rates in the 1970s). In other words, real interest rates appear to enter regimes that exhibit stability for extended periods with temporary variation around a persistent level within each regime. Regime changes are infrequent. In fact, careful econometric study has provided evidence that the real interest rate is well described by Markov regime switching [Garcia and Perron 1996].

If the mean real interest rate is highly persistent, firms may largely ignore shortrun interest rate fluctuations, altering their typical inventory level only when there seems to be a persistent change in the real interest rate. Under these conditions, econometric procedures that focus on short-run fluctuations in inventories and the interest rate - such as the older stock adjustment or the newer Euler equation and decision rule specifications - may find little evidence of a relationship.

On the other hand, firms will adjust their inventory positions if they believe there has been a change in the underlying interest rate regime. This suggests that estimation of 
the long-run relationship between the inventories and the real interest rate may be fruitful. We use two approaches. The first is simple and intuitive: we divide our sample into interest rate regimes - high, medium, and low - and calculate the mean level of (detrended) inventories in each regime. We find that inventories are significantly higher when the interest rate is low. The second approach is more sophisticated. Using the linearized Euler equation as a starting point, we derive the cointegrating relationship between inventories and the interest rate. Cointegration tests show that inventories and the interest rate are cointegrated. Estimates of the cointegrating vector uncover a strong long-run effect of the interest rate on inventories. This finding is especially striking in view of the failure to find such a relationship using specifications that focus on short-run fluctuations.

We proceed to formally model the implications of regime switching in the interest rate. Of course, it is sometimes difficult to distinguish between a transitory shock and a shift to a new persistent regime. To capture this difficulty, we assume that firms must learn the unobservable regime from observable movements in the real interest rate. Under the assumption of regime switching and learning, the model of optimal inventory choice yields a distinctive implication: inventories should be based on the firm's assessment of the probability that the economy is currently in a given interest rate regime. In particular, under the assumption of regime switching and learning, the probabilities of being in either the high or low interest rate regime should replace the interest rate in the cointegrating vector for inventories. We test this implication and find statistically significant evidence that the long-run behavior of inventories is linked to these probabilities. 
The next section presents the firm's optimization problem. Section III examines the short-run relationship between inventories and the real interest rate, introducing the new tests for the role of the interest rate based on the Euler equation and the decision rule. Section IV analyzes and tests the long-run relationship between inventories and the real interest rate. Section $\mathrm{V}$ introduces the formal model of regime switching and learning, derives the distinctive implication of the model, calculates the probabilities, and tests the implication. Section VI presents robustness checks, and Section VII concludes.

\section{The Firm's Optimization Problem}

We begin by assuming a representative firm that minimizes the present value of its expected costs over an infinite horizon. Real costs per period are assumed to be quadratic and are defined as

$$
C_{t}=\xi W_{t} Y_{t}+\frac{\theta}{2} Y_{t}^{2}+\frac{\gamma}{2}\left(\Delta Y_{t}\right)^{2}+\frac{\delta}{2}\left(N_{t-1}-\alpha X_{t}\right)^{2}
$$

where $\theta, \gamma, \delta, \xi, \alpha>0 . \mathrm{C}_{\mathrm{t}}$ denotes real costs, $\mathrm{Y}_{\mathrm{t}}$, real output, $\mathrm{N}_{\mathrm{t}}$, end-of-period real finished goods inventories, $X_{t}$, real sales, and $\mathrm{W}_{\mathrm{t}}$, a real cost shock, which we will associate with real input prices. (We do not include unobservable cost shocks, since they are not directly relevant to the relationship between inventories and the interest rate. In Section IV.B, we discuss how the modeling of unobservable cost shocks would affect the cointegrating vector.) The level of real sales, $X_{t}$, and the real cost shock, $\mathrm{W}_{\mathrm{t}}$, are given exogenously. The first two terms capture production costs. The third term is adjustment costs on output. The last term is inventory holding costs, which balance storage costs and stockout costs, where $\alpha X$, is the target stock of inventories. 
Let $\beta_{t}$ be a variable real discount factor, which is given by $\beta_{t}=\frac{1}{1+r_{t}}$, where $r_{t}$ denotes the real rate of interest. The firm's optimization problem is to minimize the present discounted value of expected costs,

$$
E_{0} \sum_{i=0}^{\infty}\left[\prod_{j=0}^{t-1} \beta_{j}\right] C_{t}
$$

subject to the inventory accumulation equation, which gives the change in inventories as the excess of production over sales,

$$
N_{t}-N_{t-1}=Y_{t}-X_{t}
$$

The Euler equation that results from this optimization problem is

$$
\begin{aligned}
& E_{t}\left\{\theta\left(Y_{t}-\beta_{t+1} Y_{t+1}\right)+\gamma\right.\left(\Delta Y_{t}-2 \beta_{t+1} \Delta Y_{t+1}+\beta_{t+1} \beta_{t+2} \Delta Y_{t+2}\right) \\
&\left.+\xi\left(W_{t}-\beta_{t+1} W_{t+1}\right)+\delta \beta_{t+1}\left(N_{t}-\alpha X_{t+1}\right)\right\}=0
\end{aligned}
$$

where from (3) $Y_{t}=N_{t}-N_{t-1}+X_{t}$. Observe that (4) involves products of the discount factor and the choice variables and products of the discount factor and the forcing variables. Linearizing these products around constant values, which may be interpreted as stationary state values or sample means, yields a linearized Euler equation:

$$
\begin{aligned}
E_{t}\left\{\theta\left(Y_{t}-\bar{\beta} Y_{t+1}\right)+\gamma\left(\Delta Y_{t}-2 \bar{\beta} \Delta Y_{t+1}+\right.\right. & \left.\bar{\beta}^{2} \Delta Y_{t+2}\right)+\xi\left(W_{t}-\bar{\beta} W_{t+1}\right) \\
& \left.+\delta \bar{\beta}\left(N_{t}-\alpha X_{t+1}\right)+\eta r_{t+1}+c\right\}=0
\end{aligned}
$$


where $\eta=\bar{\beta}(\theta \bar{Y}+\xi \bar{W})>0, c=-\bar{r} \bar{\beta}(\theta \bar{Y}+\xi \bar{W})<0, \quad \bar{\beta}=\frac{1}{1+\bar{r}}, \quad$ and a bar above a variable denotes the stationary state value. This linearized Euler equation will serve as a basic relationship that we will use in the empirical work.

\section{The Short-Run Relationship between Inventories and the Real Interest Rate}

\section{A. Euler Equation Estimation}

A common approach in empirical work on inventories is to apply rational expectations to eliminate unobservable variables and then use Generalized Methods of Moments techniques to estimate the Euler equation. We first investigate whether a shortrun relationship between inventories and the real interest rate can be found using this approach.

Assume that sales, $X_{t}$, the cost shock, $W_{t}$, and the real interest rate, $\mathrm{r}_{t}$, obey general stochastic processes. Then, use rational expectations to eliminate expectations from (5) to get

$$
\begin{aligned}
\theta\left(Y_{t}-\bar{\beta} Y_{t+1}\right)+\gamma\left(\Delta Y_{t}-2 \bar{\beta} \Delta Y_{t+1}+\right. & \left.\bar{\beta}^{2} \Delta Y_{t+2}\right)+\xi\left(W_{t}-\bar{\beta} W_{t+1}\right) \\
& +\delta \bar{\beta}\left(N_{t}-\alpha X_{t+1}\right)+\eta r_{t+1}+c=\kappa_{t}^{I}
\end{aligned}
$$

where $\kappa_{t}^{l}$ is a forecast error and $Y_{t}$ is defined by $Y_{t}=N_{t}-N_{t-1}+X_{t}$.

Since not all the structural parameters of the Euler equation are identified, we adopt the widely used normalization and set $\delta$ equal to 1 . We estimate the Euler 
equation by $\mathrm{GMM}^{4}$, using a constant, $\mathrm{Y}_{\mathrm{t}-1}, \mathrm{~W}_{\mathrm{t}-\mathrm{l}}, \mathrm{N}_{\mathrm{t}-1}, \mathrm{X}_{\mathrm{t}-1}$ and $\mathrm{r}_{\mathrm{t}-1}$ as instruments. ${ }^{5}$ All of the variables are linearly detrended. ${ }^{6}$ Inventory Euler equations have been estimated by GMM by many authors, including Durlauf and Maccini (1995), Eichenbaum (1989), Kashyap and Wilcox (1993), Kollintzas (1995), Krane and Braun (1991), Ramey (1991), and West (1986). A few papers have allowed for interest rate variation, for example, Bils and Kahn (2000), Miron and Zeldes (1988), Kahn (1992), and Ramey (1989). To the best of our knowledge, however, this paper is the first to provide parametric tests in Euler equations for possible effects of the interest rate on inventories.

Estimates of the Euler equation under the assumption of a constant interest rate are presented in the first column of Panel A of Table 1. (The version of the Euler equation relevant to these estimates is equation (4) with $\beta_{t}$ set equal to a constant.) The target inventory-sales ratio, $\alpha$, is very precisely estimated and is approximately four weeks of sales, which is plausible. Further, the estimate of the slope of marginal cost, $\theta$, is positive and significant, indicating rising marginal cost. These estimates are consistent with those found by estimating analogous Euler equations in the recent literature. Interestingly, $\xi$, the parameter associated with observable cost shocks, is positive (as theory predicts) but insignificantly different from zero. The estimated adjustment cost parameter, $\gamma$, is positive, a result that is consistent with the existence of adjustment costs, but $\gamma$ is imprecisely estimated and not significantly different from zero.

\footnotetext{
${ }^{4}$ As discussed by West (1995), estimation by GMM is valid both in the case where sales are $\mathrm{I}(0)$ and in the case where they are I(1), as long as (in the latter case) they are cointegrated. See particularly the discussion on pages 201-202.

${ }^{5}$ The interest rate is included because it appears in the Euler equation specification that allows for variation in the interest rate, and it is desirable to use a consistent set of instruments across specifications.

${ }^{6}$ The results are qualitatively similar if the Euler equation is estimated without detrending.

${ }^{7}$ See, for example, Durlauf and Maccini (1995).
} 
Estimates of the Euler equation under the assumption of a variable interest rate are presented in the second column of Table 1, Panel A. The t statistic on $\eta$ provides a simple test for the effect of the interest rate on inventories. The point estimate of $\eta$ is negative, but the coefficient is insignificantly different from zero.

Even if $\eta$ is not significantly different from zero, it is possible that allowing for a variable interest rate could improve estimates of the other parameters and, more generally, improve the fit of the Euler equation. Informally, a comparison of the first and second columns of Panel A suggests that allowing for a variable interest rate makes some quantitative difference in the estimates of the other parameters but little qualitative difference. A formal test procedure, which is based on a comparison of the overidentifying restrictions between the two models, is described by Newey and West (1987). The intuition for the test is straightforward. If a model is incorrectly specified, the $J$ statistic for the model will tend to be large; the difference in $\mathrm{J}$ statistics between two models provides a test of whether the improvement in specification is statistically significant. The difference in $\mathrm{J}$ statistics is distributed $\chi^{2}$, with degrees of freedom equal to the number of omitted parameters, here equal to one. ${ }^{8}$ The Newey-West test statistic is 2.752 , so it is not possible to reject the constant interest rate restriction.

In the remaining panels of Table 1 , we check the robustness of the results to changes in the specification of the model. In the empirical inventory literature, there is mixed evidence on the importance of adjustment costs and observable cost shocks. ${ }^{9}$ Panel B presents Euler equation estimates from a specification that includes observable

\footnotetext{
${ }^{8}$ For the test, the same weighting matrix should be used; we use the weighting matrix from the variable interest rate specification, since it is the "unrestricted" model.

${ }^{9}$ See, e.g., the surveys by Blinder and Maccini (1991), Ramey and West (1999), and West (1995).
} 
cost shocks but sets $\gamma$ to zero. Estimates of the other parameters $(\theta, \xi$, and $\alpha)$ are not dramatically affected. As in the Panel A results, the interest rate enters with a negative coefficient but is insignificantly different from zero. Also as in Panel A, the Newey-West test fails to reject the constant interest rate specification.

Panel $\mathrm{C}$ presents estimates of a specification that allows for adjustment costs but sets $\xi$ equal to zero (so observable cost shocks do not enter). Panel D presents estimates of a specification that excludes both adjustment costs and observable cost shocks. In neither case is there statistically significant evidence of a role for the interest rate.

Overall, the Euler equation results presented in this section show no evidence of a statistically significant relationship between inventories and the interest rate. This is consistent with much earlier research, which has typically found that inventories are not significantly related to the interest rate.

\section{B. Decision Rule Estimation}

An alternative approach in empirical work with inventories is to estimate the decision rule for optimal inventories that is implied by the firm's optimization problem. We next explore whether this approach can detect a short-run relationship between inventories and the real interest rate. In the appendix, we show that the linearized Euler equation, (5), may be written as a fourth-order expectational difference equation. Let $\lambda_{1}$ and $\lambda_{2}$ denote the stable roots of the relevant characteristic equation. We show in the appendix that the firm's decision rule for the optimal level of inventories can be expressed as a function of current and expected future sales, cost shocks, and the interest rate; it is given by 


$$
E_{t} N_{t}=\left(\lambda_{1}+\lambda_{2}\right) N_{t-1}-\lambda_{1} \lambda_{2} N_{t-2}+\frac{\bar{\beta} \lambda_{1} \lambda_{2}}{\left(\lambda_{1}-\lambda_{2}\right)} \sum_{j=0}^{\infty}\left[\left(\bar{\beta} \lambda_{1}\right)^{j+1}-\left(\bar{\beta} \lambda_{2}\right)^{j+1}\right] E_{t} \Psi_{t+j}
$$

where

$$
\begin{gathered}
\Psi_{t+j}=-X_{t+2+j}+\frac{1}{\gamma \bar{\beta}}[\theta+\gamma(2+\bar{\beta})] X_{t+1+j}-\frac{1}{\gamma \bar{\beta}^{2}}[\theta+\gamma(1+2 \bar{\beta})-\alpha \delta \bar{\beta}] X_{t+j} \\
+\frac{1}{\bar{\beta}^{2}} X_{t-1}-\frac{\xi}{\gamma \bar{\beta}^{2}}\left(W_{t+j}-\bar{\beta} W_{t+1+j}\right)-\frac{\eta}{\gamma \bar{\beta}^{2}} r_{t+1+j}-\frac{c}{\gamma \bar{\beta}^{2}}
\end{gathered}
$$

Assume that the firm carries out its production plans for time t, so that $E_{t} Y_{t}=Y_{t}$.

Then the inventory accumulation equation, (3), implies that $\left(N_{t}-E_{t} N_{t}\right)=-\left(X_{t}-E_{t} X_{t}\right)$, which means in effect that inventories buffer sales shocks. Define $u_{t}^{x} \equiv-\left(X_{t}-E_{t} X_{t}\right)$ as the sales forecast error, then the relationship that defines the firm's actual inventory position is

$$
N_{t}=\left(\lambda_{1}+\lambda_{2}\right) N_{t-1}-\lambda_{1} \lambda_{2} N_{t-2}+\frac{\bar{\beta} \lambda_{1} \lambda_{2}}{\left(\lambda_{1}-\lambda_{2}\right)} \sum_{j=0}^{\infty}\left[\left(\bar{\beta} \lambda_{1}\right)^{j+1}-\left(\bar{\beta} \lambda_{2}\right)^{j+1}\right] E_{t} \Psi_{t+j}+u_{t}^{x}
$$

where again $\Psi_{t+j}$ is defined by (8).

Assume now that sales, real input prices, and the real interest rate follow independent AR(1) processes, and that the current information set of the firm includes lagged values of sales, and current and lagged values of input prices and the interest rate. We show in the appendix that under these assumptions (9) gives

$$
N_{t}=\Gamma_{0}+\left(\lambda_{1}+\lambda_{2}\right) N_{t-1}-\lambda_{1} \lambda_{2} N_{t-2}+\Gamma_{X} X_{t-1}+\Gamma_{W} W_{t}+\Gamma_{r} r_{t}+u_{t}^{x} .
$$

with 


$$
\Gamma_{X} \geq 0, \quad \Gamma_{W}<0 \text {, and } \Gamma_{r}<0
$$

Note the expected sign of the coefficients in (10). The coefficient on sales is, in general, ambiguous, as it balances production smoothing and stockout avoidance. Nonetheless, based on prior empirical work, we expect a positive coefficient, which implies that we expect stockout avoidance to dominate. It follows from $\Gamma_{W}<0$ that an increase in real input prices, which increases costs, should cause a decline in inventories. An increase in the real interest rate should induce the firm to reduce inventory holdings, as implied by $\Gamma_{r}<0$.

Under the assumption made above that the stochastic process for sales is $\operatorname{AR}(1)$, the decision rule is just identified and can be estimated by OLS. (In later sections, we specifically assume a unit root process, but the result that the decision rule is just identified and can be estimated by OLS holds more generally for any AR(1) process.) Inference can be carried out with standard distributions, regardless of whether sales are $\mathrm{I}(0)$ or $\mathrm{I}(1) .^{10}$ As noted above, a number of authors have estimated the decision rule, including Blanchard (1983), Fuhrer, Moore, and Schuh (1995), and Humphreys, Maccini, and Schuh (2001). ${ }^{11}$

Based on previous studies that allow for interest rate variation, it would be mildly surprising if we found that the coefficient on the interest rate was of the theoretically

\footnotetext{
${ }^{10}$ See West (1995) for a detailed discussion of estimation and inference issues. Our estimation procedure for the decision rule is also valid if there are unobservable cost shocks (including serially correlated shocks) unless the shocks are I(I). We consider the case of $\mathrm{I}(0)$ observable cost shocks in this subsection and I(I) observable cost shocks in Section VI.

"These studies have typically estimated structural parameters via nonlinear maximum likelihood procedures, whereas in this paper we are in effect estimating reduced form parameters. However, since the relevant structural parameter connected to the real interest rate is $\eta$, and since $\eta$ appears only in the reduced form parameter $\Gamma_{r}$, the results for the role of the interest rate are unlikely to be improved by estimating structural parameters using nonlinear procedures.
} 
predicted sign and statistically significant. On the other hand, to the best of our knowledge, no one has previously reported estimates of the decision rule for inventories that allow for a variable interest rate. Prior studies that have allowed interest rate variation have estimated Euler equations.

We begin by considering the most general specification of the decision rule (allowing for both adjustment costs and observable cost shocks) in Panel A of Table 2. Under the assumption of a constant interest rate, the coefficients on all the variables in the decision rule are significantly different from zero. Further, sales has a positive coefficient, indicating that the stockout avoidance motive dominates, and real input prices have a negative coefficient, consistent with the predictions of the theory.

Under the assumption of a variable interest rate (specifically an AR(1) process for r), we see from equation (10) that the interest rate also enters the decision rule. The second column of Panel A shows that the estimated coefficient on the interest rate is positive, a result which is contrary to the implications of the linear-quadratic model of inventories with a variable interest rate, although the coefficient on the interest rate is insignificantly different from zero. Further, allowing for a variable interest rate has essentially no effect on the signs and statistical significance of the coefficients of sales, real input prices, or the lagged inventory stocks.

Panel B presents decision rule estimates from a specification that includes observable cost shocks but excludes adjustment costs. This changes the empirical specification of the decision rule, leading to the omission of the second lag of inventories. Panel $\mathrm{C}$ presents estimates of a specification that allows for adjustment costs but excludes observable cost shocks. The specification in Panel D excludes both adjustment costs and 
observable costs shocks. The estimated coefficient on the interest rate always has a positive sign, although it is important to note that the coefficient is never significantly different from zero. Moreover, the signs and statistical significance of the other variables in the decision rule are little affected by whether or not the interest rate is variable or constant. $^{12}$

It is straightforward to summarize the results from the different specifications of the decision rule: there is no evidence of a statistically significant effect of the interest rate on inventories. Again, this is consistent with most earlier research, which has failed to find a significant relationship between inventories and the interest rate.

\section{The Long-Run Relationship between Inventories and the Real Interest Rate.}

Why is it that estimates of the Euler equation and decision rule show no statistically significant effect of the real interest rate on inventories? A possible clue lies in the behavior of the interest rate. Figure 1 plots the ex-post real interest rate over the period 1961-2000. As the figure illustrates, there are long periods when the interest rate is centered around a given mean. For example, the real interest rate is centered around a value just below $2 \%$ for much of the 1960 s. In the early 1970 s, there is a shift in the mean real interest rate to a value of about $-2 \%$. The real interest rate rises sharply around 1980 and remains high (around 5\% on average) for much of the 1980s. In the late 1980s and for much of the 1990s, the real interest rate returns to a mean value that is close to its 1960s level.

\footnotetext{
${ }^{12}$ A minor exception is that the coefficient of sales is a bit more significant when the interest rate is variable. Also, note that excluding observable cost shocks seems to reduce the statistical significance of sales, suggesting that excluding cost shocks creates an omitted variable bias problem.
} 
What implication does this behavior of the interest rate have for empirical estimates of the effect of the interest rate on inventories? If the mean interest rate is highly persistent within an interest rate regime, firms may largely ignore short-run interest rate fluctuations, adapting average inventory levels only when there seems to be a persistent change in the opportunity cost of holding inventories. If this is the case, then econometric procedures that focus on short-run fluctuations in inventories and the interest rate may find little evidence of a relationship.

In this section, we focus on the long-run relationship between inventories and the interest rate. We consider two tests of the relationship. The first is a simple, intuitive test: are inventories lower on average during the high interest rate regime? The second is a more sophisticated test, based on deriving and estimating the cointegrating vector for inventories under the assumption of variable interest rates.

\section{A. Tests of Means}

Our first test of the long-run relationship between inventories and the interest rate divides the 1961-2000 period into regimes characterized by different mean interest rates. Specifically, we classify the period 1972:02-1980:02 in the low-interest-rate regime, 1980:12-1986:04 in the high-interest-rate regime, and the remaining observations in the medium-interest-rate regime. ${ }^{13}$

The results are presented in Table 3. Inventories are highest in the low-interestrate regime and lowest in the high-interest-rate regime. The level of detrended inventories is about $8 \%$ higher in the low-interest-rate regime than in the high-interest-

\footnotetext{
${ }^{13}$ This is an intuitive definition of the regimes; we introduce a foraml procedure for identifying regimes in Section V.
} 
rate regime. The difference in means between the high- and low-interest-rate regimes is highly significant. To the best of our knowledge, this is the first time that this simple test for the long-run effect of the interest rate on inventories has been reported.

\section{B. Derivation of the Cointegrating Vector}

A more sophisticated test of the long-run relationship between inventories and the interest rate is to derive the cointegrating relationship between inventories, the interest rate, and any other relevant variables. The advantage of the cointegration approach over the simple test of means presented earlier is that it accounts for the effect of variables such as sales and observable cost shocks on the long-run level of inventories.

To derive the cointegrating vector, it is helpful to rewrite the basic Euler equation, (5), in such a way as to put most of the variables in the form of first differences ${ }^{1415}$ :

$$
\begin{gathered}
E_{t}\left\{\gamma\left(\Delta Y_{t}-2 \bar{\beta} \Delta Y_{t+1}+\bar{\beta}^{2} \Delta Y_{t+2}\right)-\bar{\beta} \theta\left(\Delta N_{t+1}+\Delta X_{t+1}\right)+\theta \Delta N_{t}-\bar{\beta} \delta \alpha \Delta X_{t+1}-\bar{\beta} \xi \Delta W_{t+1}+\eta \Delta r_{t+1}\right. \\
\left.\quad+\bar{\beta} \delta\left[N_{t}-\left(\alpha-\frac{\theta(1-\bar{\beta})}{\bar{\beta} \delta}\right) X_{t}\right]+(1-\bar{\beta}) \xi W_{t}+\eta r_{t}+c\right\}=0
\end{gathered}
$$

where $Y_{i}$ is again given by (3). [For the derivation of (11) from (5), see the appendix.]

Note that we can express equation (11) as $E_{t}\left\{\chi_{t+2}\right\}=0$ for the appropriate definition of

\footnotetext{
${ }^{14}$ See Kashyap and Wilcox (1993) and Ramey and West (1999) for derivations of the cointegrating relationship for inventories under the assumption that the interest rate is constant.

15 We are agnostic on the issue of unobserved cost shocks, which are not of primary interest in this paper. As a result, we do not include a term comparable to $U_{c t}$ in Hamilton (2002) or Ramey and West (1999) in our model and thus do not address the issue of whether unobservable cost shocks are best modeled as I( 0$)$ or 1(1). Hamilton (2002) argues that, if one were to include unobservable cost shocks under his preferred assumptions, the same variables would appear in the cointegrating vector, but the coefficients would be altered. It is possible to show that his argument can be generalized to our model, which includes a timevarying interest rate and observable cost shocks. Under assumptions similar to Hamilton's, the same variables appear in our cointegrating vector. The coefficients are altered, but signs of the coefficients remain the same.
} 
$\chi_{t+2}$. Rational expectations implies that the expectation error $\phi_{t+2} \equiv \chi_{t+2}-E_{t}\left\{\chi_{t+2}\right\}$ will be serially uncorrelated and therefore cannot have a unit root; in other words $\phi_{t+2}$ is $\mathrm{I}(0)$. Since $E_{t}\left\{\chi_{t+2}\right\}=0, \quad \chi_{t+2}=\phi_{t+2}$. Since $\phi_{t+2}$ is $\mathrm{I}(0)$, $\chi_{t+2}$ will also be $\mathrm{I}(0)$. Suppose for the moment that $X_{t}, W_{t}$ and $r_{t}$ are I(1). Then $N_{t}$ will be $1(1)$ and the stationarity of $\chi_{t+2}$ implies that inventories, sales, the cost shock, and the real interest rate will be cointegrated, with cointegrating vector

$$
\left[1,-\left(\alpha-\frac{\theta(1-\bar{\beta})}{\bar{\beta} \delta}\right), \quad \frac{\xi(1-\bar{\beta})}{\bar{\beta} \delta}, \quad \frac{\eta}{\bar{\beta} \delta}\right]
$$

It is useful to note that ADF tests show $N_{t}, X_{t}, W_{t}$ and $r_{t}$ to be I(1) variables (in the usual sense that the tests fail to reject the null hypothesis of a unit root). ${ }^{16}$

From the above derivation, it follows that the cointegrating vector is the same regardless of whether adjustment costs are included in or excluded from the model. To see why, consider the first term in parentheses in equation (11), which reflects adjustment costs. Note that all the elements in this term enter in the form $\Delta Y$. Thus, if $\mathrm{Y}$ is $\mathrm{I}(1)$, all the elements in this term will be $\mathrm{I}(0)$.

The parameters $\alpha, \theta, \delta, \xi$ are assumed to be positive, and we have shown, below equation (5), that $\eta$ is positive. When the cointegrating vector is expressed in the form of a regression, $X_{t}, W_{t}$ and $r_{t+1}$ will be on the right hand side of the equation, so their coefficients will have signs opposite to those shown in the cointegrating vector above. In other words, in the long run, we expect inventories to be inversely related to

\footnotetext{
${ }^{16}$ An alternative procedure for deriving the cointegrating relationship between inventories and the forcing variables is to express the decision rule for optimal inventories in the form of a stock adjustment principle in which case the cointegrating relationship is defined by the "desired" or the "equilibrium" stock of inventories. Such a procedure yields an identical cointegrating vector.
} 
the cost shock and the real interest rate, and, if the accelerator motive for holding inventories dominates the production smoothing motive, we expect inventories to be positively related to sales.

\section{Cointegration Tests and Estimates of the Cointegrating Vector}

Johansen-Juselius tests of cointegration between inventories, sales, observable cost shocks, and the interest rate are presented in Table 4 for levels, logs, and linear detrending of the variables. The evidence is consistent with the theory: the tests reject the null hypothesis of no cointegration.

We turn next to estimation of the cointegrating vector. Our estimation procedure is DOLS as described by Stock and Watson (1993). In contrast to SOLS estimation of cointegrating vectors, DOLS corrects for biases that can arise (except under rather strong assumptions) in finite samples. In addition, Stock and Watson (1993) find that DOLS has the minimum RMSE among a set of potential estimators of cointegrating vectors. ${ }^{17}$

Table 5 presents estimates of the cointegrating vector. The interest rate enters the cointegrating relationship with a negative sign, and the t-statistic is greater than five, which is very strong evidence of a long-run relationship between inventories and the interest rate. This is a very striking result, especially when compared with the results reported above indicating no evidence of a short-run relationship between inventories and the interest rate.

\footnotetext{
${ }^{17}$ DOLS essentially adds leads and lags of the first differences of the right hand side variables to the cointegrating regression to ensure that the error term is orthogonal to the right hand side variables. (For a brief description, see, e.g., Hamilton (1994), p. 602-612.) In theory, the number of leads and lags could be infinite, but this is impractical. There is Monte Carlo evidence (for the case of fixed investment) that relatively high numbers of leads and lags are the most effective in reducing bias. Caballero (1994, p. 56) finds that the bias is smallest when the number of leads and lags is 25 for a sample size of 120 . We set the number of leads and lags to 24 . (Recall that we are using monthly data.)
} 
The point estimate of the coefficient on the interest rate (based on linearly detrended variables) is -0.016 and the difference in the interest rate between the highinterest-rate regime and the low-interest-rate regime is about $6.8 \%$. The estimated coefficient in Table 5 therefore implies a decrease in inventories of about $11 \%$ as the economy moves from the high to the low interest rate. ${ }^{18}$

It is interesting to compare these results with the findings in Table 3 . The simple comparison of means in Table 3 shows that inventories are about $8 \%$ lower in the highinterest-rate regime than in the low-interest-rate regime. Controlling for other variables, specifically sales and observable cost shocks -- as the cointegrating regression does -leads to a qualitatively similar but slightly larger effect. Inventories are about $11 \%$ lower in the high-interest-rate regime than the low-interest-rate regime.

Interestingly, cost variables enter the cointegrating regression with the theoretically predicted sign and a coefficient that is significantly different from zero, a relationship that many empirical studies that focus on short-run fluctuations fail to uncover. The estimated elasticity of inventories with respect to observable cost shocks is between -0.8 and -1.0 .

\footnotetext{
${ }^{18}$ The only previously reported cointegrating vectors for inventories which allow for a variable interest rate of which we are aware are in Rossana (1993), which uses a rather different approach. Instead of including the ex post real interest rate in the cointegrating vector, he enters the nominal interest rate and the inflation rate as separate variables and (using two-digit industry-level data) tests the restriction that the coefficients are equal in magnitude and of opposite signs. It is therefore not straightforward to determine from the results he reports whether inventories have an economically or statistically significant relationship with the real interest rate.
} 


\section{Formally Modeling Regime Switching and Learning}

In the previous section, we suggest an intuitively appealing explanation for the lack of a relationship between inventories and the real interest rate. The behavior of the real interest rate is strongly suggestive of regime shifts, with transitory variation around persistent mean interest rates. Because mean interest rates are highly persistent, firms may largely ignore short-run variation in the interest rate. Instead, firms respond to changes in interest rate when there has been a regime shift. Consistent with this explanation, two tests confirm a highly significant long-run relationship between inventories and interest rate. In this section, we go a step further. We begin by formally modeling regime shifts in the real interest rate and then show how this affects inventory behavior. This leads to a distinctive implication of regime switching and learning for the long-run behavior of inventories. In subsection $\mathrm{D}$, we test this implication.

\section{A. Regime Switching and Learning}

Regime switches can be formally modeled by assuming that the real interest rate follows

$$
r_{t}=r_{S_{t}}+\sigma_{S_{t}}-\varepsilon_{t}
$$

where $\varepsilon_{t} \sim$ i.i.d. $N(0,1)$ and $S_{t}$ is the interest rate regime (with the mnemonic $S$ for "state"). Regime-switching in the real interest rate has been formally explored by econometricians. In particular, Garcia and Perron (1996) show that the real interest rate in the U.S. is well described by a three-state Markov switching model. We therefore assume that $S_{1} \in\{1,2,3\}$ follows a Markov switching process ${ }^{19}$. Let $r_{1}<r_{2}<r_{3}$, so that when $S_{t}=1$ the real interest rate is in the low-interest-rate regime, when $S_{t}=2$ the

\footnotetext{
${ }^{19}$ For a comprehensive discussion of Markov switching processes, see Hamilton (1994, Chapter 22).
} 
real interest rate is in the moderate interest rate regime, and when $S_{t}=3$ the real interest rate is in the high-interest-rate regime. $\mathrm{S}_{\mathfrak{t}}$ and $\varepsilon_{t}$ are assumed to be independent. Denote the transition probabilities governing the evolution of $\mathrm{S}_{\mathrm{t}}$ by $p_{i j}=\operatorname{Prob}\left(S_{t}=j \mid S_{t-1}=i\right)$. Collecting these probabilities into a matrix we have

$$
P=\left[\begin{array}{lll}
p_{11} & p_{21} & p_{31} \\
p_{12} & p_{22} & p_{32} \\
p_{13} & p_{23} & p_{33}
\end{array}\right] .
$$

Interest rate regimes are not directly observable. No one announces to firms that the economy has just entered the low interest rate regime. Instead, firms must make inferences about the interest rate regime from their observations of the interest rate. In other words, firms learn about the interest rate regime.

To be precise, we assume that the firm knows the structure and parameters of the Markov switching process but does not know the true interest rate regime. The firm must therefore infer $S_{t}$ from observed interest rates. We denote the firm's current probability assessment of the true state by $\pi_{\mathrm{t}}$. That is,

$$
\pi_{t}=\left[\begin{array}{l}
\pi_{1 t} \\
\pi_{2 t} \\
\pi_{3 t}
\end{array}\right]=\left[\begin{array}{l}
\operatorname{Prob}\left(S_{t}=1 \mid \Omega_{t}\right) \\
\operatorname{Prob}\left(S_{t}=2 \mid \Omega_{t}\right) \\
\operatorname{Prob}\left(S_{t}=3 \mid \Omega_{t}\right)
\end{array}\right],
$$

where the firm's information set, $\Omega_{t}$, includes the current and past values of $r_{t}$. Here, $\pi_{i t}$ is the firm's estimate at date $\mathrm{t}$ of the probability that the real interest rate is in regime $\mathrm{i}$.

To understand the learning process, consider how the firm uses its observation of the current real interest rate to develop its probability assessment, $\pi_{t}$. Beginning at the end of period t-1 the firm uses $\pi_{t-1}$ together with the transition probabilities in $\mathrm{P}$ to form 
beliefs about the period $t$ interest rate state prior to observing $r_{t}$. That is the firm evaluates $\pi_{i t \mid-1} \equiv \operatorname{Prob}\left(\mathrm{S}_{\mathrm{t}}=i \mid \Omega_{t-1}\right)$ for $\mathrm{i}=1,2,3$ using

$$
\left[\begin{array}{l}
\pi_{1|t|-1} \\
\pi_{2|t|-1} \\
\pi_{3 \mid t-1}
\end{array}\right]=P \pi_{t-1}
$$

Once the firm enters period $t$ and observes $r_{t}$, it uses the prior probabilities from (13) together with the conditional probability densities,

$$
f\left(\mathrm{r}_{\mathrm{t}} \mid S_{t}=i\right)=\frac{1}{\sigma_{i} \sqrt{2 \pi}} \exp \left[\frac{-1}{2 \sigma_{i}^{2}}\left(\mathrm{r}_{t}-\mathrm{r}_{i}\right)^{2}\right] \text { for } i=1,2,3,
$$

to update $\pi_{t}$ according to Bayes' rule. Specifically,

$$
\pi_{i t}=\frac{\pi_{i t \mid t-1} \cdot f\left(\mathrm{r}_{t} \mid S_{t}=i\right)}{\sum_{j=1}^{3} \pi_{j t \mid t-1} \cdot f\left(\mathrm{r}_{t} \mid S_{t}=j\right)} \quad \text { for } i=1,2,3
$$

Thus, the firm uses Bayes' rule and its observations of the real interest rate to learn about the underlying interest rate regime.

Given $\pi_{t}$, the expected real interest rate, which may be interpreted as an ex ante real interest rate, may then be computed as

$$
E_{t} \mathrm{r}_{t+1}=\mathrm{r}_{\mathrm{v}}^{\prime} P \pi_{t}=\gamma_{1} \pi_{1 t}+\gamma_{2} \pi_{2 t}+\gamma_{3} \pi_{3 t}
$$

where $\mathrm{r}_{\mathrm{v}}^{\prime}=\left[\mathrm{r}_{1}, \mathrm{r}_{2}, \mathrm{r}_{3}\right], \quad \gamma_{1} \equiv p_{11} \mathrm{r}_{1}+p_{12} \mathrm{r}_{2}+p_{13} \mathrm{r}_{3}, \quad \gamma_{2} \equiv p_{21} \mathrm{r}_{1}+p_{22} \mathrm{r}_{2}+p_{23} \mathrm{r}_{3}$, and $\gamma_{3} \equiv p_{31} \mathrm{r}_{1}+p_{32} \mathrm{r}_{2}+p_{33} \mathrm{r}_{3}$. Since $\pi_{1 t}+\pi_{2 t}+\pi_{3 t}=1$ by definition, we can eliminate $\pi_{2 t}$ from the right hand side of (16) to obtain

$$
E_{t} \mathrm{r}_{t+1}=\left(\gamma_{1}-\gamma_{2}\right) \pi_{1 t}+\left(\gamma_{3}-\gamma_{2}\right) \pi_{3 t}+\gamma_{2}
$$


Now, to isolate the expected real interest rate in the linearized Euler equation, partition (5) so that

$$
\begin{aligned}
E_{t}\left\{\theta\left(Y_{t}-\bar{\beta} Y_{t+1}\right)+\gamma\left(\Delta Y_{t}-2 \bar{\beta} \Delta Y_{t+1}+\bar{\beta}^{2} \Delta Y_{t+2}\right)+\xi\left(W_{t}-\bar{\beta} W_{t+1}\right)\right. & \\
& \left.+\delta \bar{\beta}\left(N_{t}-\alpha X_{t+1}\right)\right\}+\eta E_{t} r_{t+1}+c=0 .
\end{aligned}
$$

Then, substitute (17) into (18) to get

$$
\begin{aligned}
E_{t}\left\{\theta\left(Y_{t}-\bar{\beta} Y_{t+1}\right)\right. & +\gamma\left(\Delta Y_{t}-2 \bar{\beta} \Delta Y_{t+1}+\bar{\beta}^{2} \Delta Y_{t+2}\right)+\xi\left(W_{t}-\bar{\beta} W_{t+1}\right) \\
& \left.+\delta \bar{\beta}\left(N_{t}-\alpha X_{t+1}\right)\right\}+\eta\left(\gamma_{1}-\gamma_{2}\right) \pi_{1 t}+\eta\left(\gamma_{3}-\gamma_{2}\right) \pi_{3 t}+\eta \gamma_{2}+c=0 .
\end{aligned}
$$

To summarize this sub-section, we have introduced a formal model of regime switching and learning. The key variable in the model is $\pi_{i t}$, the firm's assessment of the probability of being in interest rate regime $\mathrm{i}$, conditional on the firm's information set in period t. In the model of optimal inventory choice under the assumption of regime switching and learning, these probabilities replace the interest rate in the Euler equation. In the next subsection, we will show that this leads to a distinctive implication of regime switching and learning and then use cointegration techniques to test this implication.

\section{B. Derivation of the Distinctive Implication of Regime Switching and Learning}

We can now follow the same approach as in the Section IV.B in order to derive the long-run implication of regime switching and learning. Begin by re-writing equation (19) so that most of the variables are in first differences. 


$$
\begin{aligned}
E_{t}\left\{\gamma \left(\Delta Y_{t}-2 \bar{\beta} \Delta Y_{t+1}+\right.\right. & \left.\bar{\beta}^{2} \Delta Y_{t+2}\right)-\bar{\beta} \theta\left(\Delta N_{t+1}+\Delta X_{t+1}\right)+\theta \Delta N_{t}-\bar{\beta} \delta \alpha \Delta X_{t+1}-\bar{\beta} \xi \Delta W_{t+1} \\
& \left.+\bar{\beta} \delta\left[N_{t}-\left(\alpha-\frac{\theta(1-\bar{\beta})}{\bar{\beta} \delta}\right) X_{t}\right]+(1-\bar{\beta}) \xi W_{t}\right\} \\
& +\eta\left(\gamma_{1}-\gamma_{2}\right) \pi_{1 t}+\eta\left(\gamma_{3}-\gamma_{2}\right) \pi_{3 t}+\eta \gamma_{2}+c=0
\end{aligned}
$$

Suppose now that $X_{t}, W_{t}, \pi_{1 t}$ and $\pi_{3 t}$ are $\mathrm{I}(1){ }^{20}$ Then $N_{t}$ will be $\mathrm{l}(1)$ and inventories, sales, the cost shock, and the probabilities will be cointegrated with cointegrating vector

$$
\left[1,-\left(\alpha-\frac{\theta(1-\bar{\beta})}{\bar{\beta} \delta}\right), \frac{\xi(1-\bar{\beta})}{\bar{\beta} \delta}, \frac{\eta\left(\gamma_{1}-\gamma_{2}\right)}{\bar{\beta} \delta}, \frac{\eta\left(\gamma_{3}-\gamma_{2}\right)}{\bar{\beta} \delta}\right] \text {. }
$$

Again, note that, when the cointegrating vector is expressed in the form of a regression, $X_{t}, W_{t}, \pi_{1 t}$ and $\pi_{3 t}$ will be on the right-hand-side of the equation, so their coefficients will have signs opposite to those shown in the cointegrating vector above. We have shown earlier (just below equation (5)) that $\eta>0 .\left(\gamma_{1}-\gamma_{2}\right)$ and $\left(\gamma_{3}-\gamma_{2}\right)$ are complicated functions of the elements of $\mathrm{P}$ and $\mathrm{r}_{\mathrm{v}}$, so it is not possible to sign them unambiguously for all mathematically feasible values of $\mathrm{P}$ and $\mathrm{r}_{\mathrm{v}}$. They can, however, be signed for the empirically relevant values. Using empirical estimates of the elements of $P$ and $r_{v}{ }^{21}$ we obtain $\left(\gamma_{1}-\gamma_{2}\right)<0$ and $\left(\gamma_{3}-\gamma_{2}\right)>0$, so the model predicts that the coefficient on $\pi_{1 t}$ will be positive and the coefficient on $\pi_{3 t}$ will be negative.

This accords with our intuition of how the probabilities should affect inventories. If, for example, there is an increase in $\pi_{1 t}$, the firm believes that the economy is entering

\footnotetext{
${ }^{20}$ Since $\pi_{11}$ and $\pi_{31}$ have a restricted range, one might wonder whether it is better to model them as $1(0)$ or I(1). We note two points. First, in careful applied econometric research, variables with restricted ranges, such as the nominal interest rate, are modeled as I(1) variables when they are highly persistent. (See, e.g., Stock and Watson (1993) and Caballero (1994).) Second, unit root tests indicate that $\pi_{1 t}$ and $\pi_{31}$ are $1(1)$.

${ }^{21}$ See the next sub-section.
} 
a persistent low-interest-rate regime. This will lower the expected opportunity cost of holding inventories and should therefore lead to an increase in $\mathrm{N}_{\mathrm{t}}$. Looking at the cointegrating vector, we can see this effect. With $\eta\left(\gamma_{1}-\gamma_{2}\right)<0$, an increase in $\pi_{1 t}$ will lead to an increase in $N_{t}$ (since $\pi_{1 t}$ will be on the right hand side of the cointegrating regression). Similarly, since $\eta\left(\gamma_{3}-\gamma_{2}\right)>0$, an increase in $\pi_{3 t}$, which indicates that the firm believes the economy is entering a persistent high-interest-rate regime, will lead to a decrease in $\mathrm{N}_{\mathrm{t}}$.

Thus, the distinctive implication of regime switching and learning is that inventories will be cointegrated with the probabilities $\pi_{1 t}$ and $\pi_{3 t}$ and that the coefficient on $\pi_{1 t}$ will be positive and the coefficient on $\pi_{3 t}$ will be negative.

\section{Calculating the Probabilities $\pi_{1 \mathrm{t}}$ and $\pi_{3 \mathrm{t}}$}

In order to test the distinctive implication of regime switching and learning, we must construct the probabilities $\pi_{1 \mathrm{t}}$ and $\pi_{3 \mathrm{t}}$. This can be done using the techniques described in Hamilton (1989 and 1994, Chapter 22). We begin by estimating the parameters of a three-state Markov switching process for the real interest rate over our sample period. Our estimates of the elements of the transition probability matrix are

$$
P=\left[\begin{array}{lll}
p_{11}=0.98 & p_{21}=0.01 & p_{31}=0.00 \\
p_{12}=0.02 & p_{22}=0.98 & p_{32}=0.04 \\
p_{13}=0.00 & p_{23}=0.01 & p_{33}=0.96
\end{array}\right] .
$$

Our estimates of $r_{1}, r_{2}$, and $r_{3}$ (annualized) are $-1.71,1.61$, and 5.15, and our estimates of $\sigma_{1}, \sigma_{2}$, and $\sigma_{3}$ are $1.90,0.80$ and 1.96 , respectively. 
Two features of the behavior of the real interest rate stand out from these estimates. First, since $\mathrm{p}_{11}, \mathrm{p}_{22}$, and $\mathrm{p}_{33}$ are all close to one, the interest rate regimes are highly persistent. For example, these estimates indicate that, if the economy is in the low-interest-rate regime this period, there is a $98 \%$ probability that it will be in the lowinterest-rate regime next period. Similarly, if the economy is in the high-interest-rate regime this period, there is a $96 \%$ probability that it will be in the high-interest-rate regime next period. This suggests that changes in the interest-rate regime will occur infrequently. Furthermore, once the firm comes to believe that the economy has entered a particular interest rate regime, it will anticipate that the current regime will persist for some time.

Second, note that the difference between the mean interest rates of any two regimes is large relative to the standard deviations. For example, $r_{2}-r_{1}=3.3$, which is 1.7 times as large as the standard deviation of the white noise shock in regime one. This suggests that, within a given regime, white noise shocks that are sufficiently large to be mistaken for a regime change will not be common.

Figure 2 plots the behavior of $\pi_{1 \mathrm{t}}, \pi_{2 \mathrm{t}}$, and $\pi_{3 \mathrm{t}}$ as obtained by applying the filter in equations (13), (14), and (15) to the real interest rate data in our sample. $\left(\pi_{2 t}\right.$ is not required for subsequent tests, since the sum of the three probabilities is 1 , but we illustrate $\pi_{2 t}$ in Figure 2 for completeness.) This figure confirms that, when viewed from the perspective of the Markov switching model, most of the short-run variation in the real interest rate consists of temporary fluctuations around the mean interest rate for the current regime. For the most part, the probability of being in a given interest rate regime 
is close to 0 or 1 . Only occasionally does the Markov switching model identify shifts in the mean real interest rate.

\section{Tests of the Distinctive Implication of Regime Switching and Learning}

In Section V.B, we show that regime switching and learning have a distinctive and testable implication: inventories will be cointegrated with $\pi_{1 t}$ and $\pi_{3 t}$, the probabilities that the economy is in the low and high-interest rate regime, respectively. Johansen-Juselius tests of cointegration between inventories, sales, observable cost shocks, and the probabilities $\pi_{1 \mathrm{t}}$ and $\pi_{3 \mathrm{t}}$ are presented in Table 6 for levels, logs, and linear detrending of the variables. The evidence is consistent with regime switching and learning: the tests reject the null hypothesis of no cointegration.

Table 7 presents estimates of the coefficients in the cointegrating vector between inventories, sales, cost shocks, and the probabilities $\pi_{1 t}$ and $\pi_{3 t}$. Consistent with regimeswitching and learning, the coefficient on $\pi_{3 t}$ is negative and highly significant, implying that an increase in the probability of the high-interest-rate regime reduces inventories in the long run.

The point estimate of the coefficient on $\pi_{3 t}$ implies that an increase in the interest rate from $1.6 \%$ (the mean interest rate in the medium-interest-rate regime, which is the point of reference) to $5.1 \%$ (the mean interest rate in the high-interest-rate regime) reduces inventories by about $7 \%$. The coefficient on $\pi_{1 t}$ is positive as predicted. Although less precisely estimated, the point estimate implies a change in inventories, moving from the low-interest-rate to the middle-interest-rate regime, that is similar to the change implied by the estimates in Table 5 , a decrease in inventories of about $5 \%$. The 
estimated cumulative effect of a move from the low-interest-rate regime to the highinterest-rate regime is a decrease in inventories of about $12 \%$.

\section{Robustness Checks}

\section{A. Adjustment Costs and Observable Cost Shocks}

In Section III we examine the robustness of the Euler equation and decision rule results to the inclusion or exclusion of adjustment costs from the model. As discussed in Section IV.A, however, adjustment costs make no difference to the cointegrating vector. Intuitively, this is because adjustment costs affect dynamics in the short run but do not affect the long-run relationship.

In the inventory literature, it is sometimes assumed that cost shocks are $\mathrm{I}(0)$ and sometimes that they are I(1). (See, e.g., Hamilton (2002), Ramey and West (1999), Rossana (1993, 1998), and West (1995).) Although ADF tests suggest that observable cost shocks have a unit root, we consider both possibilities. If observable cost shocks are $\mathrm{I}(0)$, then inventories, sales, and the interest rate will be cointegrated. In Table 8 we carry out cointegration tests for the case where observable cost shocks are I(0). As Panel A of Table 8 reports, we find evidence of cointegration between inventories, sales, and the interest rate. The evidence of cointegration between inventories, sales, and the probabilities is even stronger, as shown in Panel B.

In Table 9, we estimate the cointegrating vector under the assumption that observable cost shocks are $\mathrm{I}(0)$. The coefficient on the interest rate is negative, as theory predicts, but insignificantly different from zero, as shown in Panel A. Panel B presents estimates of the cointegrating vector for the case of regime switching and learning. The 
point estimate of the coefficient on $\pi_{3 t}$ is somewhat greater than the estimate reported in

Table 7. As in Table 7, the t-statistics on $\pi_{3 t}$ are large.

We present the results in Table 9 for completeness, because the inventory literature has modeled cost shocks as both $\mathrm{I}(0)$ and $\mathrm{I}(1)$ processes, but the results in Table 7 are preferred for two reasons. First, as noted above, ADF tests suggest that observable cost shocks are I(1). Second, the coefficients on observable cost shocks in Table 7 have very large t-statistics, raising the potential of omitted variable bias if observable cost shocks are excluded from the cointegrating regression. Thus the results in Table 9 are likely to be biased due to a misspecification of the cointegrating relationship, specifically the omission of observable cost shocks.

\section{B. Serial Correlation of the Interest Rate within a Regime}

It is possible to allow for serial correlation of the interest rate within a regime through suitable modification of the Markov switching model for the interest rate. $^{22}$ Allowing for serial correlation of the interest rate within a regime has two main implications. First, it yields different time series of $\pi_{1 t}$ and $\pi_{3 t}$ (although, in practice, the resulting probabilities are fairly similar regardless of whether or not we allow for serial correlation). Second, it changes the expectation of the interest rate (i.e., $E_{t}\left[r_{t+1}\right]$ ), leading to a more complicated set of interest-rate-related variables in the Euler equation. ${ }^{23}$

Table 10 presents estimates of the cointegrating vector that allow for serial correlation of the interest rate within a regime. Again, we focus on the specification

\footnotetext{
${ }^{22}$ See Garcia and Perron (1996) for details. Following Garcia and Perron (1996), we focus on the case where the stochastic component within a regime follows an AR(2) process.

${ }^{23}$ Details of the derivation are available from the authors.
} 
including observable cost shocks. (The inclusion or exclusion of adjustment costs makes no difference to the cointegrating vector, as noted above.) As in the estimates reported in Table 7 , the point estimate of the coefficient on $\pi_{3 t}$ is negative. In fact, the absolute magnitude of the estimated coefficient on $\pi_{3 t}$ is somewhat larger in Table 10 than in Table 7. As in Table 7, the t-statistics associated with $\pi_{3 t}$ are large (in this case, around $6)$.

\section{Conclusion}

We present a variety of new evidence on the relationship between inventories and the real interest rate. First, we develop a tractable way to parametrically estimate the effect of the interest rate in the Euler equation and decision rule for inventories. Our findings parallel previous work based on the older stock adjustment model: there is little evidence of a significant role for the interest rate from the Euler equation or decision rule.

Second, we propose an explanation for the fact that the interest rate does not show up in econometric estimates, either our own or those of previous researchers. The key to our explanation is that the real interest rate shows evidence of highly persistent regimes, with transitory variation within a regime. Because of the persistence of interest rate regimes, firms do not adjust their inventories much in response to short-run variation in the interest rate. If our explanation is correct, there should be evidence of a long-run relationship between inventories and the interest rate. In fact, there is. As shown in Table 3, inventories tend to be lower when the economy is in the high-interest-rate regime. Moreover, we derive the cointegrating vector between inventories and the interest rate and find that: 1) inventories and the real interest rate (together with sales and 
observable cost shocks) are cointegrated; and 2) the estimated coefficient on the real interest rate in the cointegrating regression is statistically and economically significant.

These results are consistent with our explanation, but we go a step further. We formally model optimal inventory choice under the assumption of regime switching and learning, derive a distinctive implication from the model, and test this implication. Briefly, the implication is that inventories should be cointegrated with the probabilities of being in the high- or low-interest-rate regime. The data confirm this implication.

We view our results, which emphasize regime switching and learning, as complimentary to research that focuses on finance constraints. Finance constraints will also lead to a relationship between inventories and the interest rate that is stronger in the long run. If finance constraints are important, in the short run inventories may be more strongly influenced by financial market conditions (that are not captured by the interest rate) and by the availability of internal finance. ${ }^{24}$ For example, in 2001 and parts of 2002, the interest rate was not high, but financial market conditions made it difficult for firms to raise funds, and the economic downturn squeezed internal funds for many firms. In circumstances like these, the shadow cost of funds may be greater than the market interest rate, and the relationship between inventories and the observed interest rate may be weak. In the long run, even in the presence of finance constraints, the interest rate will still affect inventories because long-lasting periods of low or high interest rates will span different short-term financial market conditions and, when finance constraints do not bind, firms will adjust inventories to the prevailing interest rate.

\footnotetext{
${ }^{24}$ As noted above, Kashyap, Lamont, and Stein (1994), Gertler and Gilchrist (1994), and Carpenter, Fazzari, and Petersen (1994) find evidence that finance constraints are important for inventory behavior, at least for some firms.
} 
The paper can be extended in at least two directions. One is to test the model on the two-digit industries of the nondurables sector of total manufacturing. The objective is to see whether certain two-digit industries exhibit a stronger long-run relationship between inventories and the interest rate than other two-digit industries. The second and more substantial extension is to investigate empirically whether there is a long-run relationship between input inventories (materials and work-in-process inventories) and the interest rate and to include the durable goods sector as well as the nondurable goods sector. Humphreys, Maccini, and Schuh (2001) establish several stylized facts that emphasize the importance of such an extension. Specifically, they show that input inventories are larger and more volatile than output inventories in manufacturing, and that durable goods input inventories are larger and more volatile than nondurable goods input inventories. Such an extension requires a substantial extension of the model to include input inventories as well as output inventories, but it would permit an empirical analysis of the sensitivity of the highly volatile level of input inventories to the interest rate. 


\section{REFERENCES}

Akhtar, M.A. (1983), "Effects of Interest Rates and Inflation on Aggregate Inventory Investment in the United States", American Economic Review 73, 319-28.

Bils, M. and J. Kahn, (2000), "What Inventory Behavior Tells Us about Business Cycles", American Economic Review, 90, 458-481

Blanchard, O.J. (1983), "The Production and Inventory Behavior of the American Automobile Industry", Journal of Political Economy, 91, 365-400.

Blinder, A. S. (1982), "Inventories and Sticky Prices: More on the Microfoundations of Macroeconomics", American Economic Review, 72, 3, 334-49.

Blinder, Alan S. (1986 a), "More on the Speed of Adjustment in Inventory Models", Journal of Money, Credit, and Banking, 18, 3, 355, 365.

Blinder, Alan S. (1986b), "Can the Production Smoothing Model of Inventory Behavior Be Saved?", Quarterly Journal of Economics, 101, 3, 431,53.

Blinder, A.S. and L.J. Maccini (1991), "Taking Stock: A Critical Assessment of Recent Research on Inventories", Journal of Economic Perspectives, 5,73-96.

Caballero R.J., (1994), "Small Sample Bias and Adjustment Costs," Review of Economics and Statistics, 76, 52-58.

Carpenter, R. E., S. M. Fazzari, and B.C. Petersen (1994) "Inventory Investment, Internal-finance Fluctuations, and the Business Cycle", Brookings Papers on Economic Activity, 2, 75-138.

Durlauf, S.N. and L.J. Maccini (1995), "Measuring Noise in Inventory Models", Journal of Monetary Economics, 36, 65-89.

Eichenbaum, M.S. (1989), "Some Empirical Evidence on the Production Level and Production Cost Smoothing Models of Inventory Investment", American Economic Review, 79, 853-64.

Fuhrer, J.C., G.R. Moore and S. Schuh (1995), "Estimating the Linear-quadratic Inventory Model: Maximum Likelihood versus Generalized Method of Moments", Journal of Monetary Economics 35, 115-57.

Garcia, R. and P. Perron (1996), "An Analysis of the Real Interest Rate under Regime Shifts", Review of Economics and Statistics, 78, 111-125

Gertler, M. and C. Gilchrist (1994), "Monetary Policy, Business Cycles, and the Behavior of Small Manufacturing Firms", Quarterly Journal of Economics 109(2), 309-40. 
Hamilton, J. D. (2002), "On the Interpretation of Cointegration in the Linear-Quadratic Inventory Model”, Journal of Economic Dynamics and Control, 26, 2037-49.

Hamilton, J. D. (1989), "A New Approach to the Economic Analysis of Nonstationary Time Series and the Business Cycle", Econometrica, 57, 357-84.

Hamilton, J. D. (1994), Time Series Analysis, (Princeton University Press).

Holt, C.C., F. Modigliani, J.F. Muth and H.A. Simon (1960), Planning, Production, Inventories and Work Force, (Prentice Hall, Englewood Cliffs, NJ).

Humphreys, B. R., L. J. Maccini and S. Schuh (2001), "Input and Output Inventories", Journal of Monetary Economics, 47, 347-375.

Irvine, F. Owen, (1981) Retail Inventory Investment and the Cost of Capital, American Economic Review, 70, 4, 633-48.

Kahn, J.A. (1992), "Why Is Production More Volatile Than Sales? Theory and Evidence on the Stockout-Avoidance Motive for Inventory-Holding", Quarterly Journal of Economics, 107, 481-510.

Kashyap, Anil K. and David W. Wilcox, (1990) "Production and Inventory Control at the General Motors Corporation in the 1920s and 1930s", American Economic Review 83, 383-401.

Kashyap, Anil K., O. Lamont, and J. Stein (1994), "Credit Conditions and the Cyclical Behavior of Inventories", Quarterly Journal of Economics, 109(3), 565-92.

Kollintzas, T. (1995), "A Generalized Variance Bounds Test, with an Application to the Holt et al.Inventory Model", Journal of Economic Dynamics and Control, 19, 59-90.

Krane, Spencer and Steven Braun (1991), "Production Smoothing Evidence from Physical Product Data", Journal of Political Economy, 99, 558-81.

Lovell, Michael C. (1961), "Manufacturer's Inventories, Sales Expectations, and the Acceleration Principle", Econometrica, 29, 3, 293-314.

Maccini, L.J. and R.J. Rossana (1984), "Joint Production, Quasi-Fixed Factors of Production, and Investment in Finished Goods Inventories", Journal of Money, Credit, and Banking, 16, 218-236.

Miron, J.A. and S.P. Zeldes (1988), "Seasonality, Cost Shocks and the Production Smoothing Model of Inventories", Econometrica, 56, 877-908. 
Newey, W. and K. D. West (1987), "A Simple, Positive Definite, Heteroscdasticity and Autocorrelation Consistent Covariance Matrix", Econometrica, 55, 703-8.

Ramey, V.A. and K.D. West (1999), "lnventories", in J.B. Taylor and M. Woodford (eds.), Handbook of Macroeconomics, (Amsterdam: North-Holland).

Ramey, Valerie A. (1989), "Inventories as Factors of Production and Economic Fluctuations", American Economic Review, 79, 3, 338-54.

Ramey, Valerie A. (1991), "Nonconvex Costs and the Behavior of Inventories", Journal of Political Economy, 99, 306-34.

Rossana, R.J. (1990), "Interrelated Demands for Buffer Stocks and Productive Inputs: Estimation for Two-digit Manufacturing Industries," Review of Economics and Statistics, 72, 19-29.

Rossana, R.J. (1993), "The long-run Implications of the Production Smoothing Model of Inventories: an Empirical Test", Journal of Applied Econometrics, 8, 295-306.

Rossana, R.J. (1998), "Structural Instability and the Production Smoothing Model of Inventories", Journal of Business and Economic Statistics, 16, 206-215.

Stock, J.H., and M.W. Watson (1993), "A Simple Estimator of Cointegrating Vectors in Higher Order Integrated Systems", Econometrica, 61, 783-820.

West, K.D. (1986), "A Variance Bound Test of the Linear-Quadratic Inventory Model", Journal of Political Economy, 94, 374-401.

West, K.D. (1995), "Inventory Models", in M. Peseran and M. Wickens, eds., Handbook of Applied Econometrics, Volume I (Basil Blackwell, Oxford), 188-220. 


\section{APPENDIX A}

Derivation of Equation (7). Using (3) in (5) the linearized Euler equation can be written as the following fourth- order difference equation in $\mathrm{N}_{\mathrm{t}}$ :

$$
\begin{aligned}
& E_{t}\left\{\theta\left[N_{t}-N_{t-1}+X_{t}-\bar{\beta}\left(N_{t+1}-N_{t}+X_{t+1}\right)\right]+\gamma\left[N_{t}-N_{t-1}-\left(N_{t-1}-N_{t-2}\right)+X_{t}-X_{t-1}\right.\right. \\
& \left.-2 \bar{\beta}\left(N_{t+1}-N_{t}-\left(N_{t}-N_{t-1}\right)+X_{t+1}-X_{t}\right)+\bar{\beta}^{2}\left(N_{t+2}-N_{t+1}-\left(N_{t+1}-N_{t}\right)+X_{t+2}-X_{t+1}\right)\right] \\
& \left.\quad+\xi\left(W_{t}-\bar{\beta} W_{t+1}\right)+\delta \bar{\beta}\left(N_{t}-\alpha X_{t}\right)+\eta r_{t+1}+c\right\}=0 .
\end{aligned}
$$

Rearranging we have

$$
E_{t}\left[f(L) N_{t+2}\right]=E_{t} \Psi_{t}
$$

where

$$
\begin{aligned}
f(L) \equiv 1-\frac{1}{\gamma \bar{\beta}}[\theta+2(1+\bar{\beta}) \gamma] L+\frac{1}{\gamma \bar{\beta}^{2}}[\theta(1+\bar{\beta}) & \left.+\gamma\left(1+4 \bar{\beta}+\bar{\beta}^{2}\right)+\delta \bar{\beta}\right] L^{2} \\
& -\frac{1}{\gamma \bar{\beta}^{2}}[\theta+2 \gamma(1+\bar{\beta})] L^{3}+\frac{1}{\bar{\beta}^{2}} L^{4}
\end{aligned}
$$

and

$$
\begin{gathered}
\Psi_{t}=-X_{t+2}+\frac{1}{\gamma \bar{\beta}}[\theta+\gamma(2+\bar{\beta})] X_{t+1}-\frac{1}{\gamma \bar{\beta}^{2}}[\theta+\gamma(1+2 \bar{\beta})-\alpha \delta \bar{\beta}] X_{t} \\
+\frac{1}{\bar{\beta}^{2}} X_{t-1}-\frac{\xi}{\gamma \bar{\beta}^{2}}\left(W_{t}-\bar{\beta} W_{t+1}\right)-\frac{\eta}{\gamma \bar{\beta}^{2}} r_{t+1}-\frac{c}{\gamma \bar{\beta}^{2}} .
\end{gathered}
$$

Let $\lambda_{i}, \mathrm{i}=1,2,3,4$, denote the roots of the fourth-order polynomial on the left-hand side of (A.1). Order these roots as $\left|\lambda_{1}\right|<\left|\lambda_{2}\right|<\left|\lambda_{3}\right|<\left|\lambda_{4}\right|$. It follows that $\lambda_{4}=\frac{1}{\bar{\beta} \lambda_{1}}$ and $\lambda_{3}=\frac{1}{\bar{\beta} \lambda_{2}}$, with $\left|\lambda_{1}\right|,\left|\lambda_{2}\right|<\frac{1}{\bar{\beta}}$. Suppose further that $\left|\lambda_{1}\right|,\left|\lambda_{2}\right|<1$.

Solve the unstable roots forward to obtain 
39

$$
E_{t} N_{t}=\left(\lambda_{1}+\lambda_{2}\right) N_{t-1}-\lambda_{1} \lambda_{2} N_{t-2}+\frac{\bar{\beta} \lambda_{1} \lambda_{2}}{\left(\lambda_{1}-\lambda_{2}\right)} \sum_{j=0}^{\infty}\left[\left(\bar{\beta} \lambda_{1}\right)^{j+1}-\left(\bar{\beta} \lambda_{2}\right)^{j+1}\right] E_{t} \Psi_{t+j}
$$

Note that $\lambda_{1}$ and $\lambda_{2}$ are either real or complex conjugates, so that $\lambda_{1}+\lambda_{2}$ and $\lambda_{1} \lambda_{2}$ are real.

Derivation of (10). To resolve the forward sum on the right-hand side of (9) note that we assume that sales and input prices follow AR(1) processes:

$X_{t}=\mu_{x}+\rho_{x} X_{t-1}+\varepsilon_{x t}$, where $\varepsilon_{x t}-$ i.i.d. $\left(0, \sigma_{x}^{2}\right)$ and

$W_{t}=\mu_{w}+\rho_{w} W_{t-1}+\varepsilon_{w t}$, where $\varepsilon_{w}-$ i.i.d. $\left(0, \sigma_{w}^{2}\right)$.

We allow for the special case of $\rho_{x}=\rho_{w}=1$.

1.) The terms involving $X$ on the right-hand side of (9) can be written as

$$
\frac{\bar{\beta} \lambda_{1} \lambda_{2}}{\left(\lambda_{1}-\lambda_{2}\right)}\left\{\sum_{j=0}^{\infty}\left[\left(\bar{\beta} \lambda_{1}\right)^{j+1}-\left(\bar{\beta} \lambda_{2}\right)^{j+1}\right] E_{t}\left(-X_{t+2+j}+a_{1} X_{t+1+j}-a_{0} X_{t+j}+\frac{1}{\bar{\beta}^{2}} X_{t-1+j}\right)\right\}
$$

where $a_{1} \equiv \frac{1}{\gamma \bar{\beta}}[\theta+\gamma(2+\bar{\beta})]$ and $a_{0} \equiv \frac{1}{\gamma \bar{\beta}^{2}}[\theta+\gamma(1+2 \bar{\beta})-\alpha \delta \bar{\beta}]$.

Note that, for $\mathrm{j}=0,1,2, \ldots, E_{t} X_{t+j}=\mu_{x}+\rho_{x} E_{t} X_{t-1+j}$

$$
E_{t} X_{t+j+1}=\mu_{x}\left(1+\rho_{x}\right)+\rho_{x}^{2} E_{t} X_{t-1+j} \text {, and } E_{t} X_{t+2+j}=\mu_{x}\left(1+\rho_{x}+\rho_{x}^{2}\right)+\rho_{x}^{3} E_{t} X_{t-1+j}
$$

It therefore follows that

$$
\begin{aligned}
& E_{t}\left(-X_{t+2+j}+a_{1} X_{t+1+j}-a_{0} X_{t+j}+\frac{1}{\bar{\beta}^{2}} X_{t-1+j}\right)= \\
& {\left[-\left(1+\rho_{x}+\rho_{x}^{2}\right)+a_{1}\left(1+\rho_{x}\right)-a_{0}\right] \mu_{x}+\left(-\rho_{x}^{3}+a_{1} \rho_{x}^{2}-a_{0} \rho_{x}+\frac{1}{\bar{\beta}^{2}}\right) E_{t} X_{t-1+j}}
\end{aligned}
$$

and thus, 


$$
\begin{aligned}
\sum_{j=0}^{\infty}\left(\bar{\beta} \lambda_{i}\right)^{j+1} E_{t}\left(-X_{t+2+j}+a_{1} X_{t+1+j}-a_{0} X_{t+j}+\frac{1}{\bar{\beta}^{2}} X_{t-1+j}\right) & =\frac{\bar{\beta} \lambda_{i}\left[-\left(1+\rho_{x}+\rho_{x}^{2}\right)+a_{1}\left(1+\rho_{x}\right)-a_{0}\right]}{1-\bar{\beta} \lambda_{i}} \mu_{x} \\
& +\beta \lambda_{i}\left(-\rho_{x}^{3}+a_{1} \rho_{x}^{2}-a_{0} \rho_{x}+\frac{1}{\bar{\beta}^{2}}\right) \sum_{j=0}^{\infty}\left(\beta \lambda_{i}\right)^{j} E_{t} X_{t-1+j}
\end{aligned}
$$

For the AR(1) process governing $X_{t}$, the forward sum in (A.3) is

$$
\sum_{j=0}^{\infty}\left(\bar{\beta} \lambda_{i}\right)^{j} E_{t} X_{t-1+j}=\frac{\bar{\beta} \lambda_{i} \mu_{x}}{\left(1-\bar{\beta} \lambda_{i}\right)\left(1-\bar{\beta} \lambda_{i} \rho_{x}\right)}+\frac{1}{\left(1-\bar{\beta} \lambda_{i} \rho_{x}\right)} X_{t-1}
$$

This in (A.3) gives

$$
\begin{aligned}
& \sum_{j=0}^{\infty}\left(\beta \lambda_{i}\right)^{j+1} E_{t}\left(-X_{t+2+j}+a_{1} X_{t+1+j}-a_{0} X_{t+j}+\frac{1}{\bar{\beta}^{2}} X_{t-1+j}\right)= \\
& \quad c\left(\rho_{x}, \lambda_{i}\right) \mu_{x}+\bar{\beta} \lambda_{i}\left(-\rho_{x}^{3}+a_{1} \rho_{x}^{2}-a_{0} \rho_{x}+\frac{1}{\bar{\beta}^{2}}\right)\left(1-\bar{\beta} \lambda_{i} \rho_{x}\right)^{-1} X_{t-1}
\end{aligned}
$$

where

$$
c\left(\rho_{x}, \lambda_{i}\right) \equiv \frac{\beta \lambda_{i}\left[-\left(1+\rho_{x}+\rho_{x}^{2}\right)+a_{1}\left(1+\rho_{x}\right)-a_{0}\right]}{1-\beta \lambda_{i}}+\frac{\left(\bar{\beta} \lambda_{i}\right)^{2}\left(-\rho_{x}^{3}+a_{1} \rho_{x}^{2}-a_{0} \rho_{x}+\bar{\beta}^{-2}\right)}{\left(1-\bar{\beta} \lambda_{i}\right)\left(1-\bar{\beta} \lambda_{i} \rho_{x}\right)}
$$

Using (A.4) we can rewrite the term (A.2) as

$$
\begin{gathered}
\frac{\bar{\beta} \lambda_{1} \lambda_{2}}{\left(\lambda_{1}-\lambda_{2}\right)}\left\{\sum_{j=0}^{\infty}\left[\left(\beta \lambda_{1}\right)^{j+1}-\left(\beta \lambda_{2}\right)^{j+1}\right] E_{t}\left(-X_{t+2+j}+a_{1} X_{t+1+j}-a_{0} X_{t+j}+\frac{1}{\bar{\beta}^{2}} X_{t-1+j}\right)\right\} \\
=c_{X}+\Gamma_{X} X_{t-1}
\end{gathered}
$$

where $c_{X} \equiv \frac{\bar{\beta} \lambda_{1} \lambda_{2}}{\left(\lambda_{1}-\lambda_{2}\right)}\left[c\left(\rho_{x}, \lambda_{1}\right)-c\left(\rho_{x}, \lambda_{2}\right)\right] \mu_{x} \quad$ and

$$
\Gamma_{X} \equiv \bar{\beta}^{2} \lambda_{1} \lambda_{2}\left(-\rho_{x}^{3}+a_{1} \rho_{x}^{2}-a_{0} \rho_{x}+\bar{\beta}^{-2}\right)\left[\frac{1}{\left(1-\bar{\beta} \lambda_{1} \rho_{x}\right)\left(1-\bar{\beta} \lambda_{2} \rho_{x}\right)}\right]
$$


2.) Proceeding as with the terms in $X$, the terms involving $W$ on the right-hand side of (18) can be written as

$$
\begin{aligned}
& \left(-\frac{\xi}{\gamma \bar{\beta}}\right) \frac{\lambda_{1} \lambda_{2}}{\left(\lambda_{1}-\lambda_{2}\right)}\left\{\sum_{j=0}^{\infty}\left[\left(\bar{\beta} \lambda_{1}\right)^{j+1}-\left(\bar{\beta} \lambda_{2}\right)^{j+1}\right] E_{t}\left(W_{t+j}-\bar{\beta} W_{t+1+j}\right)\right\}=c_{W}+\Gamma_{W} W_{i} \\
& \text { where } c_{W} \equiv\left(-\frac{\xi}{\gamma \bar{\beta}}\right) \frac{\lambda_{1} \lambda_{2}}{\left(\lambda_{1}-\lambda_{2}\right)}\left[c\left(\rho_{w}, \lambda_{1}\right)-c\left(\rho_{w}, \lambda_{2}\right)\right] \mu_{w}, \\
& c\left(\rho_{w}, \lambda_{i}\right) \equiv\left[\frac{-\bar{\beta}^{2} \lambda_{i}}{1-\bar{\beta} \lambda_{i}}+\frac{\left(\bar{\beta} \lambda_{i}\right)^{2}\left(1-\bar{\beta} \rho_{w}\right)}{\left(1-\bar{\beta} \lambda_{i}\right)\left(1-\bar{\beta} \lambda_{i} \rho_{w}\right)}\right] \mu_{w} \text {, and } \\
& \Gamma_{W} \equiv\left(-\frac{\xi}{\gamma}\right) \lambda_{1} \lambda_{2}\left[\frac{\left(1-\bar{\beta} \rho_{w}\right)}{\left(1-\bar{\beta} \lambda_{1} \rho_{w}\right)\left(1-\bar{\beta} \lambda_{2} \rho_{w}\right)}\right] . \text { Note that if } \lambda_{1} \lambda_{2}>0 \text { then } \Gamma_{W}<0 .
\end{aligned}
$$

3.) Similarly, assuming that $\mathrm{r}_{\mathrm{t}}$ follows $r_{t}=\mu_{r}+\rho_{r} r_{t-1}+\varepsilon_{r t}$, where $\varepsilon_{r t}-i . i . d .\left(0, \sigma_{r}^{2}\right)$, we obtain that

$$
\left(-\frac{\eta}{\gamma \bar{\beta}}\right) \frac{\lambda_{1} \lambda_{2}}{\left(\lambda_{1}-\lambda_{2}\right)}\left\{\sum_{j=0}^{\infty}\left[\left(\bar{\beta} \lambda_{1}\right)^{j+1}-\left(\bar{\beta} \lambda_{2}\right)^{j+1}\right] E_{t} r_{t+1+j}\right\}=c_{r}+\Gamma_{r} r_{t}
$$

where

$$
c_{r} \equiv\left(-\frac{\eta}{\gamma}\right) \lambda_{1} \lambda_{2}\left\{\left(\frac{1}{\left(1-\bar{\beta} \lambda_{1}\right)\left(1-\bar{\beta} \lambda_{2}\right)}\right)+\rho_{r}\left[\frac{\left(\bar{\beta} \lambda_{1}\right)^{2}}{\left(1-\bar{\beta} \lambda_{1}\right)\left(1-\bar{\beta} \lambda_{1} \rho_{r}\right)}-\frac{\left(\bar{\beta} \lambda_{2}\right)^{2}}{\left(1-\bar{\beta} \lambda_{2}\right)\left(1-\bar{\beta} \lambda_{2} \rho_{r}\right)}\right]\right\} \mu_{r}
$$

and $\Gamma_{r} \equiv\left(-\frac{\eta}{\gamma}\right)\left(\lambda_{1} \lambda_{2}\right) \frac{\rho_{r}}{\left(1-\bar{\beta} \lambda_{1} \rho_{r}\right)\left(1-\bar{\beta} \lambda_{2} \rho_{r}\right)}$. Note that, if $\lambda_{1} \lambda_{2}>0$ then $\Gamma_{r}<0$.

\section{4.) Finally,}

$$
\left(\frac{-1}{\gamma \bar{\beta}^{2}}\right) \frac{\bar{\beta} \lambda_{1} \lambda_{2}}{\left(\lambda_{1}-\lambda_{2}\right)}\left\{\sum_{j=0}^{\infty}\left[\left(\bar{\beta} \lambda_{1}\right)^{j+1}-\left(\bar{\beta} \lambda_{2}\right)^{j+1}\right] c\right\}=\frac{-\lambda_{1} \lambda_{2}}{\gamma\left(1-\bar{\beta} \lambda_{1}\right)\left(1-\bar{\beta} \lambda_{2}\right)} c .
$$


5.) Using the results from (A.5), (A.6), (A.7), and (A.8) in (9) we have

$$
N_{t}=\Gamma_{0}+\left(\lambda_{1}+\lambda_{2}\right) N_{t-1}-\lambda_{1} \lambda_{2} N_{t-2}+\Gamma_{X} X_{t-1}+\Gamma_{W} W_{t}+\Gamma_{r} r_{t}+u_{t}^{x},
$$

where $\Gamma_{0}=c_{W}+c_{X}+c_{r}+\frac{-\lambda_{1} \lambda_{2}}{\left(1-\bar{\beta} \lambda_{1}\right)\left(1-\bar{\beta} \lambda_{2}\right)} c$,

and where $\quad \Gamma_{X} \frac{\geq}{<} 0 \quad \Gamma_{W}<0 \quad \Gamma_{r}<0$.

\section{Equation (10) in the Model without Adjustment Costs.}

In the model with $\gamma=0$ equation (3) in (5) yields a second-order difference equation in $\mathrm{N}_{t}$ that has one stable and one unstable root. Denoting the stable root by $\lambda_{1}$, equation (10) becomes

$$
N_{1}=\Gamma_{0}+\lambda_{1} N_{t-1}+\Gamma_{X} X_{t-1}+\Gamma_{W} W_{t}+\Gamma_{r} r_{t}+u_{t}^{x},
$$

where $\Gamma_{X} \equiv\left(\frac{-\lambda_{1}}{\theta}\right)\left[\theta \rho_{x}-(\theta \bar{\beta}+\alpha \delta \bar{\beta}) \rho_{x}^{2}\right]\left(\frac{1}{1-\bar{\beta} \lambda_{1} \rho_{x}}\right)$

$\Gamma_{W} \equiv\left(\frac{-\lambda_{1}}{\theta}\right) \xi\left(1-\bar{\beta} \rho_{w}\right)\left(\frac{1}{1-\bar{\beta} \lambda_{1} \rho_{w}}\right), \quad$ and $\quad \Gamma_{r} \equiv\left(\frac{-\lambda_{1}}{\theta}\right) \eta \rho_{r}\left(\frac{1}{1-\bar{\beta} \lambda_{1} \rho_{r}}\right)$

\section{Derivation of Equation (11).}

Use equation (3) to substitute for $Y_{t}$ and $Y_{t+1}$ in equation (5) and rearrange to get 


$$
\begin{aligned}
& E_{t}\left\{\gamma\left(\Delta Y_{t}-2 \bar{\beta} \Delta Y_{t+1}+\bar{\beta}^{2} \Delta Y_{t+2}\right)-\bar{\beta} \theta\left(\Delta N_{t+1}+\Delta X_{t+1}\right)+\theta \Delta N_{t}-\bar{\beta} \delta \alpha \Delta X_{t+1}\right. \\
& \left.+\xi\left(W_{t}-\bar{\beta} W_{t+1}\right)+\delta \bar{\beta}\left[N_{t}-\left(\alpha-\frac{\theta(1-\bar{\beta})}{\bar{\beta} \delta}\right) X_{t}\right]+\eta r_{t+1}+c\right\}=0 .
\end{aligned}
$$

Use $\xi\left(W_{t}-\bar{\beta} W_{t+1}\right)=-\bar{\beta} \xi \Delta W_{t+1}+(1-\bar{\beta}) \xi W_{t}$ and $\eta r_{t+1}=\eta \Delta r_{t+1}+\eta r_{t}$ in (A.11) to get (11). 


\section{APPENDIX B}

\section{Data Description}

The real inventory and shipments data are produced by the Bureau of Econoic Analysis and are derived from the Census Bureau's Maunfacturers' Shipments, Inventories, and Orders survey. They are seasonally adjusted, expressed in millions of 1996 chained dollars, and cover the period 1959:01-1999:02. An implicit price index for shipments is obtained from the ratio of nominal shipments to real shipments.

The observable cost shocks include average hourly earnings of production and nonsupervisory workers for the nominal wage rate; materials price indexes constructed from two-digit producer price indexes and input-output relationships (See Humphreys, Maccini and Schuh (2001) for details); and crude oil prices as a measure of energy prices. Nominal input prices were converted to real values using the shipments deflator. The nominal interest rate is the 3-month Treasury bill rate. Real rates were computed by deducting the three-month inflation rate calculated by the Consumer Price Index. 
Table 1

Euler Equation Estimates

Panel A: Including Adjustment Costs and Observable Cost Shocks

\begin{tabular}{|l|c|c|}
\hline$\theta$ & $\begin{array}{c}\text { Constant Interest } \\
\text { Rate }\end{array}$ & $\begin{array}{c}\text { Variable Interest } \\
\text { Rate }\end{array}$ \\
\hline$\gamma$ & 6.210 & 11.113 \\
$(2.042)$ & $(2.071)$ \\
\hline$\xi$ & 1.026 & 1.098 \\
$(0.593)$ & $(0.433)$ \\
\hline$\alpha$ & 0.814 & 1.185 \\
& $(0.469)$ & $(0.484)$ \\
\hline$\eta$ & 1.060 & 1.317 \\
& $(7.334)$ & $(4.691)$ \\
\hline Constant & & -.659 \\
& & $(-1.407)$ \\
\hline Newey-West & $(-.347)$ & 0.142 \\
test & & $(0.599)$ \\
\hline
\end{tabular}

Panel B: Including Observable Cost Shocks but no Adjustment Costs

\begin{tabular}{|l|c|c|}
\hline & $\begin{array}{c}\text { Constant Interest } \\
\text { Rate }\end{array}$ & $\begin{array}{c}\text { Variable Interest } \\
\text { Rate }\end{array}$ \\
\hline$\theta$ & 6.482 & 15.072 \\
$(2.637)$ & $(2.331)$ \\
\hline$\xi$ & 1.172 & 1.359 \\
$(0.797)$ & $(0.497)$ \\
\hline$\eta$ & 1.068 & 1.513 \\
& $(9.181)$ & $(4.609)$ \\
\hline Constant & & -1.003 \\
& & $(-1.780)$ \\
\hline Newey-West & & 0.283 \\
test & & $(1.045)$ \\
\hline
\end{tabular}

Point estimates and (t statistics). The last row reports the Newey-West statistic, which tests the constant interest rate specification against the specification in column two; the pvalue is reported in square brackets. 
Table 1

Euler Equation Estimates

Panel C: Including Adjustment Costs but no Observable Cost Shocks

\begin{tabular}{|l|c|c|}
\hline & $\begin{array}{c}\text { Constant Interest } \\
\text { Rate }\end{array}$ & $\begin{array}{c}\text { Variable Interest } \\
\text { Rate }\end{array}$ \\
\hline$\theta$ & 7.714 & 12.401 \\
$(2.752)$ & $(2.527)$ \\
\hline$\gamma$ & 0.912 & 1.035 \\
$(0.467)$ & $(0.377)$ \\
\hline$\alpha$ & 1.094 & 1.376 \\
& $(7.450)$ & $(4.921)$ \\
\hline$\eta$ & & -.687 \\
& & $(-1.377)$ \\
\hline Constant & -.023 & 0.199 \\
& $(-.183)$ & $(0.856)$ \\
\hline Newey-West & & 2.074 \\
test & & {$[0.150]$} \\
\hline
\end{tabular}

Panel D: Excluding Observable Cost Shocks and Adjustment Costs

\begin{tabular}{|l|c|c|}
\hline & $\begin{array}{c}\text { Constant Interest } \\
\text { Rate }\end{array}$ & $\begin{array}{c}\text { Variable Interest } \\
\text { Rate }\end{array}$ \\
\hline$\theta$ & 8.495 & 17.091 \\
$(3.191)$ & $(2.591)$ \\
\hline$\alpha$ & 1.131 & 1.611 \\
& $(8.702)$ & $(4.611)$ \\
\hline Constant & & -1.060 \\
& -.003 & $(-1.695)$ \\
\hline Newey-West & $(-.030)$ & 0.370 \\
test & & $(1.318)$ \\
\hline
\end{tabular}

Point estimates and ( $\mathrm{t}$ statistics). The last row reports the Newey-West statistic, which tests the constant interest rate specification against the specification in column two; the pvalue is reported in square brackets. 
Table 2

Decision Rule Estimates

Panel A: Including Adjustment Cost and Observable Cost Shocks

\begin{tabular}{|c|c|c|}
\hline & $\begin{array}{c}\text { Constant Interest } \\
\text { Rate }\end{array}$ & Variable Interest Rate \\
\hline Constant & 0.032 & 0.031 \\
& $(4.206)$ & $(3.306)$ \\
\hline $\mathrm{N}_{\mathrm{t}-1}$ & 1.072 & 1.072 \\
& $(23.548)$ & $(23.514)$ \\
\hline $\mathrm{N}_{\mathrm{t}-2}$ & -.114 & -.114 \\
& $(-2.529)$ & $(-2.526)$ \\
\hline $\mathrm{X}_{\mathrm{t}-1}$ & 0.045 & 0.045 \\
& $(3.736)$ & $(3.733)$ \\
\hline $\mathrm{W}_{\mathrm{t}}$ & -.034 & -.034 \\
& $(-4.126)$ & $(-3.798)$ \\
\hline $\mathrm{r}_{\mathrm{t}}$ & \multicolumn{2}{|c}{} \\
\end{tabular}

Panel B: Including Observable Cost Shocks, no Adjustment Costs

\begin{tabular}{|c|c|c|}
\hline & $\begin{array}{c}\text { Constant Interest } \\
\text { Rate }\end{array}$ & Variable Interest Rate \\
\hline Constant & 0.034 & 0.033 \\
& $(4.451)$ & $(3.482)$ \\
\hline $\mathrm{N}_{\mathrm{t}-1}$ & 0.959 & 0.960 \\
& $(101.04)$ & $(99.052)$ \\
\hline $\mathrm{X}_{\mathrm{t}-1}$ & 0.043 & 0.043 \\
& $(3.615)$ & $(3.612)$ \\
\hline $\mathrm{W}_{\mathrm{t}}$ & -.036 & -.036 \\
& $(-4.333)$ & $(-3.979)$ \\
\hline $\mathrm{r}_{\mathrm{t}}$ & & 0.002 \\
& & $(0.10175)$ \\
\hline
\end{tabular}

OLS Estimate of Decision Rule with (t-statistic) 
Table 2

Decision Rule Estimates

Panel C: Including Adjustment Cost, no Observable Cost Shocks

\begin{tabular}{|c|c|c|}
\hline & Constant Rate & Variable Rate \\
\hline Constant & 0.013 & 0.007 \\
& $(2.073)$ & $(0.969)$ \\
\hline $\mathrm{N}_{\mathrm{t}-1}$ & 1.108 & 1.105 \\
& $(24.377)$ & $(24.330)$ \\
\hline $\mathrm{N}_{\mathrm{t}-2}$ & -.130 & -.127 \\
& $(-2.844)$ & $(-2.784)$ \\
\hline $\mathrm{X}_{\mathrm{t}-1}$ & 0.010 & 0.015 \\
& $(1.137)$ & $(1.645)$ \\
\hline $\mathrm{r}_{\mathrm{t}}$ & & 0.024 \\
& & $(1.583)$ \\
\hline
\end{tabular}

Panel D: Excluding Observable Cost Shocks and Adjustment Costs

\begin{tabular}{|c|c|c|}
\hline & Constant Rate & Variable Rate \\
\hline Constant & 0.014 & 0.007 \\
& $(2.227)$ & $(1.045)$ \\
\hline $\mathrm{N}_{\mathrm{t}-1}$ & 0.981 & 0.980 \\
& $(118.369)$ & $(118.570)$ \\
\hline $\mathrm{X}_{\mathrm{t}-1}$ & 0.006 & 0.012 \\
& $(0.729)$ & $(1.313)$ \\
\hline $\mathrm{r}_{\mathrm{t}}$ & & 0.026 \\
& & $(1.682)$ \\
\hline
\end{tabular}

OLS Estimate of Decision Rule with (t-statistic) 
Table 3: Means of Linearly Detrended Inventories in Different Interest Rate Regimes

\begin{tabular}{|l|l|l|l|c|}
\hline \multirow{2}{*}{} & \multicolumn{2}{|l|}{ Interest Rate Regime } & \multirow{2}{*}{ Test Statistic } \\
\cline { 2 - 4 } & Low & Medium & High & \\
\hline $\begin{array}{l}\text { Mean Log } \\
\text { Inventories } \\
\text { (Detrended) }\end{array}$ & 10.405 & 10.341 & 10.327 & 0.077 \\
& & & & $(5.34)$ \\
{$[0.000]$}
\end{tabular}

The cells under Interest Rate Regime report the mean of linearly detrended inventories (in logs). The last column reports the difference in means between the high and low interest rate regimes, the (t-statistic), and the [p-value], where the t-statistic is based on Newey-West standard errors (allowing for an MA(12) error term) from a regression of linearly detrended inventories (in logs) on a constant and dummies for high and low interest rate regimes. Test results are similar for quadratic detresnding and an MA(24). 
Table 4

Cointegration Tests

Inventories, Sales, Observable Cost Shocks and the Interest Rate

\begin{tabular}{|l|l|l|l|}
\hline & \multicolumn{4}{l|}{ Null hypothesis: that the number of cointegration vectors is } \\
\hline & 0 & $\leq 1$ & $\leq 2$ \\
\hline Levels & 50.011 & 27.528 & 7.854 \\
& {$[0.035]$} & {$[0.129]$} & {$[0.636]$} \\
\hline Logs & 68.733 & 35.984 & 15.872 \\
& {$[0.000]$} & {$[0.015]$} & {$[0.094]$} \\
\hline Linear detrending & 77.879 & 41.795 & 19.151 \\
& {$[0.000]$} & {$[0.002]$} & {$[0.034]$} \\
\hline
\end{tabular}

Johansen-Jeselius test statistics with p-values in square brackets. 
Table 5

Estimated Cointegrating Vector

Inventories, Sales, Observable Cost Shocks, and the Interest Rate

\begin{tabular}{|l|c|l|l|l|l|}
\hline & Constant & Time & X & r & W \\
\hline Levels & 60901.23 & 10.248 & 0.351 & -1070.78 & -401.814 \\
& $(5.46)$ & $(0.36)$ & $(2.44)$ & $(-5.11)$ & $(-5.55)$ \\
& {$[0.000]$} & {$[0.720]$} & {$[0.015]$} & {$[0.000]$} & {$[0.000]$} \\
\hline Logs & 3.407 & 10.248 & 1.000 & -0.015 & -0.843 \\
& $(2.60)$ & $(-1.51)$ & $(8.029)$ & $(-5.19)$ & $(-5.27)$ \\
& {$[0.010]$} & {$[0.132]$} & {$[0.000]$} & {$[0.000]$} & {$[0.000]$} \\
\hline Linearly & 0.891 & -.000 & 1.069 & -0.016 & -0.922 \\
Detrended & $(5.40)$ & $(-0.82)$ & $(8.76)$ & $(-5.33)$ & $(-5.84)$ \\
& {$[0.000]$} & {$[0.415]$} & {$[0.000]$} & {$[0.000]$} & {$[0.000]$} \\
\hline
\end{tabular}

DOLS estimates of the cointegrating vector with (t-statistic) and [p-values]. 
Table 6

Cointegration Tests

Inventories, Sales, Observable Cost Shocks and the Probabilities

\begin{tabular}{|l|l|l|l|}
\hline & \multicolumn{3}{|l|}{ Null hypothesis: that the number of cointegration vectors is } \\
\hline & 0 & $\leq 1$ & $\leq 2$ \\
\hline Levels & 94.11 & 54.94 & 32.33 \\
& {$[0.002]$} & {$[0.047]$} & {$[0.082]$} \\
\hline Logs & 91.68 & 57.88 & 35.97 \\
& {$[0.003]$} & {$[0.024]$} & {$[0.033]$} \\
\hline Linear detrending & 92.37 & 58.11 & 35.95 \\
& {$[0.003]$} & {$[0.023]$} & {$[0.033]$} \\
\hline
\end{tabular}

Johansen-Jeselius test statistics with p-values in square brackets. 
Table 7

Estimated Cointegrating Vector

Inventories, Sales, Observable Cost Shocks, and the Probabilities

\begin{tabular}{|l|c|l|l|l|l|l|}
\hline & Constant & Time & $\mathrm{X}$ & $\pi_{1}$ & $\pi_{3}$ & $\mathrm{~W}$ \\
\hline Levels & 51839.61 & 41.767 & 0.237 & 3845.719 & -5.263 & -301.177 \\
& $(2.82)$ & $(1.03)$ & $(1.06)$ & $(1.73)$ & $(-6.36)$ & $(-4.34)$ \\
& {$[0.005]$} & {$[0.306]$} & {$[0.289]$} & {$[0.085]$} & {$[0.000]$} & {$[0.000]$} \\
\hline Logs & 2.722 & 41.767 & 0.970 & 0.052 & -0.072 & -0.647 \\
& $(1.02)$ & $(-0.36)$ & $(4.64)$ & $(1.35)$ & $(-4.23)$ & $(-4.12)$ \\
& {$[0.308]$} & {$[0.722]$} & {$[0.000]$} & {$[0.178]$} & {$[0.000]$} & {$[0.000]$} \\
\hline Linearly & 0.679 & 0.000 & 1.015 & 0.056 & -0.073 & -0.707 \\
Detrended & $(2.29)$ & $(1.52)$ & $(4.74)$ & $(1.37)$ & $(-4.32)$ & $(-4.51)$ \\
& {$[0.023]$} & {$[0.131]$} & {$[0.000]$} & {$[0.171]$} & {$[0.000]$} & {$[0.000]$} \\
\hline
\end{tabular}

DOLS estimates of the cointegrating vector with (t-statistic) and [p-values]. 
Table 8

Cointegration Tests

Inventories, Sales, and Interest-Rate-Related Variables

Panel A: Variable Interest Rate

\begin{tabular}{|l|l|l|l|}
\hline & \multicolumn{3}{|c|}{ Null hypothesis: that the number of cointegrating vectors is } \\
\hline & 0 & $<=1$ & $<=2$ \\
\hline Levels & 39.93 & 19.56 & 3.17 \\
& {$[0.012]$} & {$[0.031]$} & {$[0.071]$} \\
\hline Logs & 38.95 & 16.23 & 6.38 \\
& {$[0.015]$} & {$[0.094]$} & {$[0.010]$} \\
\hline Linear Detrending & 38.84 & 15.82 & 6.05 \\
& {$[0.015]$} & {$[0.107]$} & {$[0.012]$} \\
\hline
\end{tabular}

Panel B: Regime-Switching and Learning

\begin{tabular}{|l|l|l|l|}
\hline \multirow{2}{*}{ Levels } & \multicolumn{3}{|l|}{ Null hypothesis: that the number of cointegrating vectors is } \\
\cline { 2 - 4 } & 0 & $\leq 1$ & $\leq 2$ \\
\hline Logs & 71.52 & 34.77 & 12.64 \\
& {$[0.001]$} & {$[0.047]$} & {$[0.258]$} \\
\hline Linear detrending & 68.46 & 36.48 & 20.43 \\
& {$[0.001]$} & {$[0.029]$} & {$[0.023]$} \\
\hline & 68.13 & 35.97 & 19.81 \\
& {$[0.002]$} & {$[0.033]$} & {$[0.028]$} \\
\hline
\end{tabular}

Johansen-Juselius test statistics with p-values in square brackets. 
Table 9

Estimated Cointegrating Vector

Inventories, Sales, and Interest-Rate-Related Variables

Panel A: Variable Interest Rate

\begin{tabular}{|l|c|l|l|l|}
\hline & Constant & Time & X & r \\
\hline Levels & 15288.81 & 62.082 & 0.213 & -499.931 \\
& $(0.56)$ & $(0.81)$ & $(0.52)$ & $(-0.80)$ \\
& {$[0.574]$} & {$[0.421]$} & {$[0.606]$} & {$[0.425]$} \\
\hline Logs & 0.584 & 62.082 & 0.879 & -0.005 \\
& $(0.16)$ & $(0.73)$ & $(2.65)$ & $(-0.65)$ \\
& {$[0.876]$} & {$[0.465]$} & {$[0.009]$} & {$[0.518]$} \\
\hline Linearly & 0.099 & 0.000 & 0.904 & -0.005 \\
Detrended & $(0.27)$ & $(0.09)$ & $(2.61)$ & $(-0.54)$ \\
& {$[0.789]$} & {$[0.931]$} & {$[0.010]$} & {$[0.589]$} \\
\hline
\end{tabular}

Panel B: Regime-Switching and Learning

\begin{tabular}{|l|l|l|l|l|l|}
\hline & Constant & Time & $X$ & $\pi_{1}$ & $\pi_{3}$ \\
\hline Levels & -16692 & -32.84 & 0.733 & -3686 & -4227 \\
& $(-0.97)$ & $(-0.61)$ & $(2.56)$ & $(-1.50)$ & $(-3.07)$ \\
& {$[0.335]$} & {$[-0.545]$} & {$[0.011]$} & {$[0.135]$} & {$[0.002]$} \\
\hline Logs & -5.803 & -32.84 & 1.454 & -0.078 & -0.094 \\
& $(-1.94)$ & $(-1.15)$ & $(5.39)$ & $(-1.89)$ & $(-3.24)$ \\
& {$[0.053]$} & {$[0.250]$} & {$[0.000]$} & {$[0.072]$} & {$[0.001]$} \\
\hline Linearly & -0.476 & 0.000 & 1.410 & -0.087 & -0.094 \\
Detrended & $(-1.73)$ & $(0.70)$ & $(5.23)$ & $(-1.84)$ & $(-3.08)$ \\
& {$[0.085]$} & {$[0.482]$} & {$[0.000]$} & {$[0.067]$} & {$[0.002]$} \\
\hline
\end{tabular}

DOLS estimates of the cointegrating vector with (t-statistic) and [p-values]. 
Table 10

Estimated Cointegrating Vector

Allowing Serial Correlation of the Interest Rate within a Regime Including Observable Cost Shocks

\begin{tabular}{|l|c|c|c|c|c|c|}
\hline & Constant & Time & $\mathrm{X}$ & $\pi_{1}$ & $\pi_{3}$ & $\mathrm{~W}$ \\
\hline Levels & 601.618 & -13.790 & 0.602 & -2211.669 & -5556.076 & -63.431 \\
& $(0.105)$ & $(-1.098)$ & $(9.528)$ & $(-3.384)$ & $(-6.474)$ & $(-1.579)$ \\
& {$[0.916]$} & {$[0.274]$} & {$[0]$} & {$[0.001]$} & {$[0]$} & {$[0.116]$} \\
\hline Logs & -0.920 & 0.000 & 1.141 & -0.021 & -0.112 & -0.279 \\
& $(-0.899)$ & $(-1.876)$ & $(14.743)$ & $(-1.224)$ & $(-5.932)$ & $(-2.430)$ \\
& {$[0.369]$} & {$[0.062]$} & {$[0]$} & {$[0.22203]$} & {$[0]$} & {$[0.016]$} \\
\hline Linearly & 0.177 & 0.000 & 1.188 & -0.019 & -0.117 & -0.337 \\
Detrended & $(1.329)$ & $(-1.433)$ & $(14.963)$ & $(-1.069)$ & $(-5.989)$ & $(-2.967)$ \\
& {$[0.185]$} & {$[0.153]$} & {$[0]$} & {$[0.286]$} & {$[0]$} & {$[0.003]$} \\
\hline
\end{tabular}

DOLS estimates of the cointegrating vector with (t-statistic) and [p-values]. 


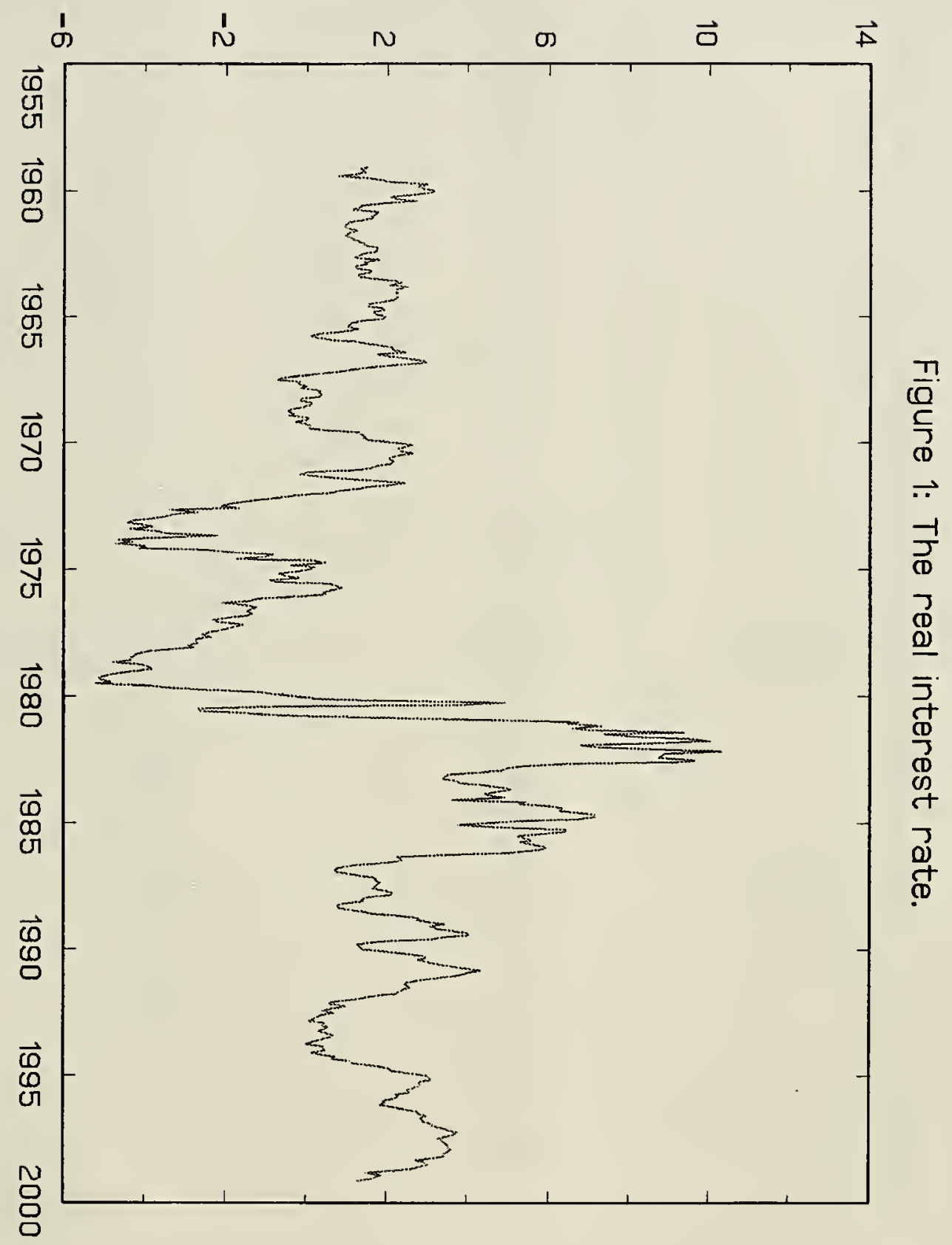




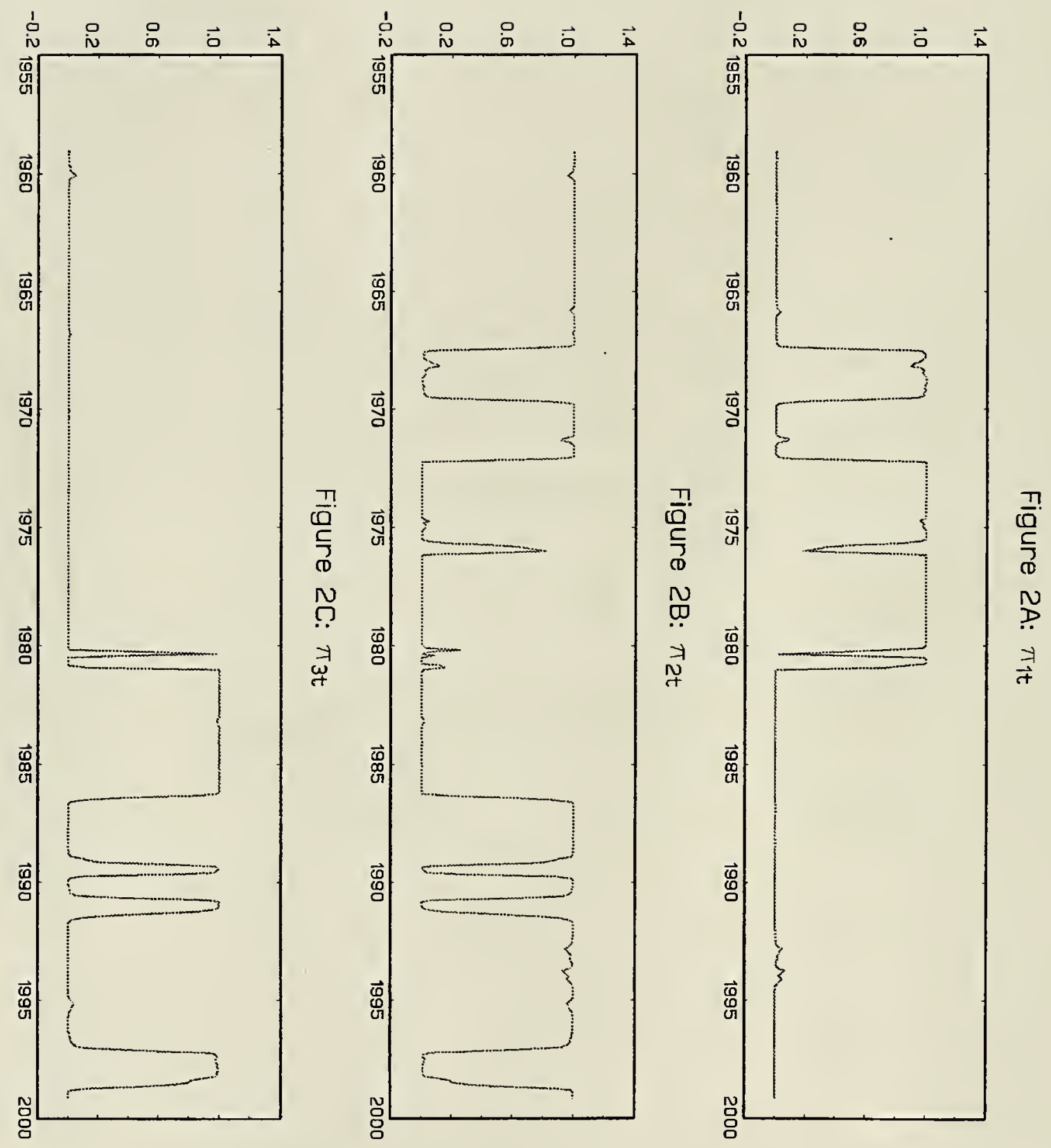




39080026184454 
